SH. Roberts, CJ. Axon, NH. Goddard, BD. Foran, \& BS. Warr (2019). Modelling socio-economic and energy data to generate business-as-usual scenarios for carbon emissions. J. Cleaner Production, 207, pp.980-997. https://doi.org/10.1016/j.jclepro.2018.10.029

\title{
Modelling socio-economic and energy data to generate business-as-usual scenarios for carbon emissions
}

\author{
Simon H. Roberts* \\ Arup, 13 Fitzroy Street, London W1T 4BQ, UK. Simon.Roberts@arup.com
}

\section{Colin J. Axon}

Institute of Energy Futures, Brunel University, London UB8 3PH, UK.

Colin.Axon@Brunel.ac.uk

\author{
Nigel H. Goddard \\ School of Informatics, University of Edinburgh, 10 Crichton Street, Edinburgh EH8 9AB, Scotland. \\ Nigel.Goddard@ed.ac.uk
}

\section{Barney D. Foran}

Institute of Land Water and Society, Charles Sturt University, PO Box 789, Albury, NSW 2640, Australia. bforan@csu.edu.au

\section{Benjamin S. Warr ${ }^{1}$}

Executive in Residence, INSEAD Social Innovation Center, Europe Campus, Boulevard de Constance, 77305

Fontainebleau, France, bwarr@sun.ac.za

* Corresponding author.

The UK Government is legally committed to achieving an $80 \%$ reduction in carbon dioxide emissions compared with 1990 by 2050. The use of scenarios is wide ranging to inform policy development and forming a businessas-usual scenario helps to understand possible effects of different policy interventions. However, the term business-as-usual is frequently misused. We show how econo-physical business-as-usual scenarios can be developed by examining the historical behaviour of coefficients which manifest the relationship between components of an economy. We endogenise economic growth by mimicking national level policies that focus on a target level of unemployment. Our case-study demonstrates the 'trendability' of coefficients which for one example coefficient is replicated for Australia, Colombia, Taiwan and the USA. We manifest a gross domestic product growth of $2 \%$ falling to $1 \%$ which contrasts with an exogenous growth of $2.3 \%$ of a comparator business-as-usual scenario. We suggest that it may be possible to achieve a greater reduction in the business-asusual carbon dioxide emissions in the UK fifth carbon budget than currently projected.

Keywords: Business as usual, Carbon budget, Carbon emissions, Productivity, Econo-physical scenarios, System dynamics.

\footnotetext{
${ }^{1}$ Currently at: Faculty of AgriSciences, Stellenbosch University, Private Bag X1, 7602 Matieland, South Africa.
} 
SH. Roberts, CJ. Axon, NH. Goddard, BD. Foran, \& BS. Warr (2019). Modelling socio-economic and energy data to generate business-as-usual scenarios for carbon emissions. J. Cleaner Production, 207, pp.980-997. https://doi.org/10.1016/j.jclepro.2018.10.029

\section{Software availability}

Name of software

Contact

Programming environment

Availability

Download URL

Year first available

Hardware required

Software required

Program size

\section{7see-GB}

Dr. Simon H. Roberts (corresponding author)

Vensim

Freely available as a Vensim Reader version. The full model is also freely available from the corresponding author.

http://dx.doi.org/10.7488/ds/1574

2016

2.0 GHz processor with 2 Gb memory

Windows (XP/Vista/7/8/8.1) or Macintosh OSX (10.4+)

$10 \mathrm{Mb}$

\section{Abbreviations}

@bp
@pp
@rc
agri
cnstr
$d w l g$
extr
manu
serv LR
trans
util

\section{Acronyms}

AFC

BAU

CCC

CCGT

CFC

CVM

DN

FC

FCF

GDP

GFCF

GHG

HGV

$\mathrm{HN}$

IC

ISIC

JPC

LCV

pGFCF coefficient

PIM

pq coefficient

SNA

TTM at basic prices (of goods and services)

at purchasers' prices (of goods and services)

at resale cost (of fixed capital)

agriculture industry, $j=1$

construction industry, $j=5$

dwellings, $j=7$

extraction industry, $j=2$

manufacturing industry, $j=4$

service industry less rental, $j=6$

transport, $j=8$

utility industry, $j=3$

actual final consumption

business-as-usual

Committee on Climate Change

combined cycle gas turbine

consumption of fixed capital

chain volume measure

number of dwellings

fixed capital

fixed capital formation

gross domestic product

gross fixed capital formation

greenhouse gases

heavy goods vehicles

number of $\mathrm{HGV}$

intermediate consumption

International Standard Industrial Classification

jobs production coefficient

light commercial vehicles

proportion of GFCF provided by final products from either of manu, cnstr or $\operatorname{serv} L R$

perpetual inventory method

conversion of output $p$ (as categorised by industry) to output $q$ (as categorised by product)

System of National Accounts

transport and trade margins 
SH. Roberts, CJ. Axon, NH. Goddard, BD. Foran, \& BS. Warr (2019). Modelling socio-economic and energy data to generate business-as-usual scenarios for carbon emissions. J. Cleaner Production, 207, pp.980-997. https://doi.org/10.1016/j.jclepro.2018.10.029

\section{Nomenclature}

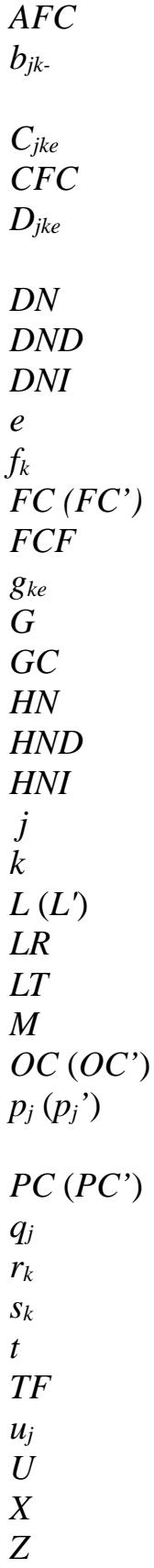

actual final consumption

proportion of products $q_{j}+M_{j}$ from industry $j$ used by industry $k$ for final products $k$

$\mathrm{CO}_{2}$ emissions by industry $j$ to final product $k$ as used by final expenditure type $e$ consumption of fixed capital of an industry

$\mathrm{CO}_{2}$ emissions by industry $j$ to final product $k$ as used by final expenditure type $e$ taking into account net emissions of FCF of producing industries

number of dwellings

dwelling number decrease

dwelling number increase

numbering of type of final expenditure

final supply, at purchasers' prices, of product $k$

fixed capital of an industry (indexed to the year when $u=0$ )

fixed capital formation of an industry

final demand, at purchasers' prices

electricity used

generating capacity

number of $\mathrm{HGV}$

HGV number decrease

HGV number increase

numbering of industries, products and other stocks and flows

numbering of products in their final form for final consumption

labour (indexed to the year when $u=0$ )

linear rate for trending of coefficients

lifetime of FC

imports

output coefficient (indexed to the year when $u=0$ )

production by industry, as classified by industry, at basic prices (indexed to the year when $u=0$ )

production coefficient (indexed to the year when $u=0$ )

production as $p$ but classified by products, at basic prices

production directly following IC, at basic prices

production $r$ after transfer from services of TTM, at basic prices

time in years

time factor for trending of coefficients

time in years with respect to most recent historical data of industry / stock type $j$

demand for TTM services

exports

horizontal asymptote 
SH. Roberts, CJ. Axon, NH. Goddard, BD. Foran, \& BS. Warr (2019). Modelling socio-economic and energy data to generate business-as-usual scenarios for carbon emissions. J. Cleaner Production, 207, pp.980-997. https://doi.org/10.1016/j.jclepro.2018.10.029

\section{Introduction}

Evidence for the effects of greenhouse gas (GHG) emissions has been mounting (IPCC, 2015) leading most nations to devise strategies to reduce their overall emissions, culminating in a set of Intended Nationally Determined Contributions (INDCs) agreed at the $21^{\text {st }}$ Conference of the Parties in Paris (UNFCCC, 2016). Furthermore, many nations have devised targets for deploying renewable energy systems (Jaccard et al., 2012). According to Oliver et al. (2016) the UK accounts for approximately $1.1 \%$ of global $\mathrm{CO}_{2}$ emissions. The UK Government is legally committed, by the Climate Change Act of 2008, to achieving an $80 \%$ reduction in $\mathrm{CO}_{2}$ emissions compared with 1990 by 2050 (HM Government, 2008). Methods for investigating pathways to emissions reduction targets should reflect the important physical, social, and economic characteristics. The physical components of an economy are buildings, plant, machinery, and other infrastructure, also referred to as fixed capital (FC). Tensions between these characteristics stem from social-political hurdles, economic growth, planetary bio-physical capacity, ecosystem burdens, and the onset of climate change (Bithas and Kalimeris, 2013; Csereklyei and Stern, 2015; Lenzen et al., 2016). Resolving these tensions requires a transparent numerate method that is evidence and factually based in the historical record; any model should be able to mimic historical behaviours and reproduce historical data.

The UK Government's commitment has inspired a considerable amount of work in understanding what pathways and the means by which the UK can reach the target e.g. DECC (2010), Hughes and Strachan (2010), Burt (2011), Ekins et al. (2011), Skea et al. (2011), Allen and Chatterton (2013), Spataru et al. (2015), Trutnevyte et al. (2016), Demski et al. (2017). However, the dominant UK energy systems models aim to find the least cost pathways (Ekins et al., 2011) leading to normative scenarios (Pfenninger et al., 2014). A wellconsidered overview of energy system scenarios relevant to the UK has been conducted by Holland et al. (2016). The range of modelling methods used to generate these scenarios has been reviewed by Jebaraj and Iniyan (2006) and Pfenninger et al. (2014). The categorisation of models by Pfenninger et al. is particularly helpful: optimisation, simulation, power markets, and mixed methods. Each type has strengths and weaknesses, for example DECC et al. (2015) point out that some optimisation models such as MARKAL suffer from cost double-counting, and that they should calculate system cost consistent with GDP accountancy. Nevertheless, MARKAL has been influential in the UK (Daly and Fais, 2014; Taylor et al., 2014). Development of MARKAL lead to the TIMES family of models (Loulou et al., 2005; Loulou and Labriet, 2008). Such hybrid models linking the energy systems optimisation models with a partial or fully equilibrium economic model have been created (Strachan and Kannan, 2008; McDowall et al., 2018). The equilibrium state is for price of energy supply and demand, and not the supply and demand for goods and services within a complete economic framework of the ability of an economy to invest in infrastructure. Although effective at answering narrow well-posed questions involving prices, the assumptions upon which such modelling methods are based can lead to projections which are not firmly rooted in physical reality.

The Climate Change Act also established the Committee on Climate Change (CCC) and the 'carbon budget' mechanism. The CCC is an independent, statutory body to advise the UK Government on reducing greenhouse gas emissions. The CCC suggests the carbon budgets ahead of time to allow for policy to be devised,

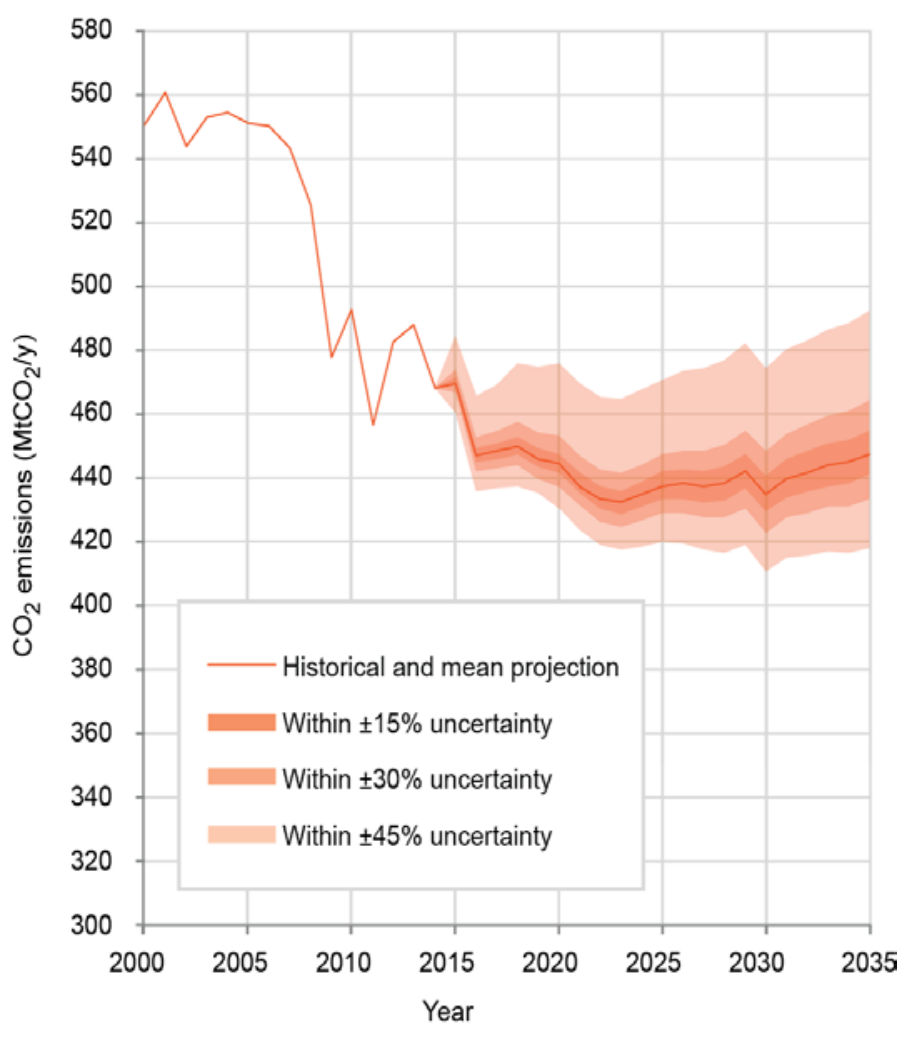

Figure 1. $\mathrm{CO}_{2}$ emissions as historical data and projection with uncertainty banding. Source: Figure 4.13 of Cambridge Econometrics (2015). 
SH. Roberts, CJ. Axon, NH. Goddard, BD. Foran, \& BS. Warr (2019). Modelling socio-economic and energy data to generate business-as-usual scenarios for carbon emissions. J. Cleaner Production, 207, pp.980-997. https://doi.org/10.1016/j.jclepro.2018.10.029

and report progress on the targets (CCC, 2017). As of 2016 it is the fifth carbon budget, covering emissions reductions for the period 2028 to 2032 (CCC, 2015), which is under consideration and was accepted by the UK Government in July 2016. The budget is set at $1765 \mathrm{MtCO}_{2} / \mathrm{y}$ equivalent (including international shipping emissions) for the period 2028-2032. This would be approximately 57\% below the 1990 level. The CCC commissioned an investigation into the uncertainty of their business-as-usual (BAU) scenario (Cambridge Econometrics, 2015). Cambridge Econometrics used their MDM-E3 model (Barker, 1978, 1981; Barker et al., 1980; Barker and Peterson, 1987) which combines input-output data and econometric modelling giving interactions between output, employment, consumption, investment, trade, prices and wages (Barker et al., 2007). MDM-E3 does not assume that resources are used at full economic efficiency. So far, only the $\mathrm{CO}_{2}$ emissions have been published (see Fig. 1) (Cambridge Econometrics, 2015). Their uncertainty bandings combine the uncertainty range of model error for each year in the projection, and the uncertainty range from variation in exogenous input assumptions: economic activity, energy prices, air temperature, and uncertainty in price elasticity of demand.

These energy systems modelling techniques lack methods for how a national economy manages the demand for new infrastructure i.e. how fixed capital formation (FCF) is generated. Modelling energy systems mediated by energy price alone cannot inform policymakers or investors of what practical rates of infrastructure development might be possible, nor what consequences of infrastructure spending might have throughout an economy. The models described so far depend on many important parameters to be supplied by the modeller (based on judgement) i.e. the parameters are treated as exogenous. Whilst all models need exogenous parameters to varying degrees, models should be designed to endogenise parameters whenever possible. Furthermore, timeseries data should be used for as many parameters as possible, and be calibrated and tested using historical data. Fixed capital formation can be treated as an explicit flow within a model (Roberts et al., 2016), which is overlooked by most energy system model developers.

A suitable modelling approach for complex socio-economic systems with feedback and interactions between population, employment, housing, industry, transport, and energy demand and supply, is system dynamics (Radzicki, 1988; Sterman, 2000). System dynamics has been used to model several important elements such as the energy use by (Icelandic) housing (Fazeli and Davidsdottir, 2017), (international) sustainable energy supply chains (Saavedra et al., 2018), capital investment in (Chinese) public transport (Xue et al., 2017), major $\mathrm{CO}_{2}$ emitting industries (e.g. Anand et al., 2006), social, economic and environmental aspects of the (Colombian) electricity industry (Castaneda et al., 2017), employment from expanded (German) biogas production (Guenther-Lübbers et al., 2016), and (Italian) employment and low-carbon investment (Bernardo and D’Alessandro, 2016). We introduce our novel system dynamics model (7see-GB) in section 2.

Another point of confusion in energy systems (scenario) modelling is the use of different terms to mean the same idea, which can make direct comparison between scenarios difficult. We need to first distinguish how the (mis-) luse of the terms 'business-as-usual' (BAU), 'reference case', 'baseline', and other terms can lead to a lack of transparency in energy systems scenario modelling. Then we will introduce a specific issue with economic modelling techniques - the forecasting of GDP - which is essential for considering FCF as a flow in an economy.

\subsection{Scenario and the Forecasting of GDP Growth}

The use of scenarios is wide ranging, whether for business planning, military strategy, or to inform policy development for example (Heijden, 2004). The techniques for scenario planning have diverged from Pierre Wack's original methods (Chermack and Coons, 2015), often to try to make the process faster or more efficient (cheaper). Chermack and Coons contend that this has led to disappointment in the results from such inadequate practices. Furthermore, Mai et al. (2013) warn of the need to check for underlying biases in published scenarios (not just in the context of energy systems analysis), and Holland et al. (2016) point out that most UK Government-supported scenarios are usually aligned with the statutory emissions targets implying a lack of diversity in approach. Questions formulated as "how is it possible to reach the target", become a form of backcasting analysis (Robinson, 1982; Dreborg, 1996). A clear description of the differences between fore- and back-casting is given by Banister and Hickman (2013). The backcasting method has been used for creating scenarios of energy use and GHG emissions for the $2{ }^{\circ} \mathrm{C}$ global temperature target (Krewitt et al., 2007), resilience in energy systems (Kishita et al., 2017), $\mathrm{CO}_{2}$ emissions from road transport (Hickman et al., 2010), 
SH. Roberts, CJ. Axon, NH. Goddard, BD. Foran, \& BS. Warr (2019). Modelling socio-economic and energy data to generate business-as-usual scenarios for carbon emissions. J. Cleaner Production, 207, pp.980-997. https://doi.org/10.1016/j.jclepro.2018.10.029

technological choices for energy systems (Beugin and Jaccard, 2012), low carbon pathways (Nagy and Körmendi, 2012; Robertson, 2016), and roadmapping in the power industry (Wen et al., 2017).

Where confusion arises is in the use of terms to describe the 'benchmark' scenario which is then used to compare the possible futures that the analyst wishes to discuss. Bishop et al. (2007) state that forming a baseline by which to compare alternative scenarios is an important stage in forecasting, with one technique being trend extrapolation. In the policy context we need a baseline scenario to see if the projected (extrapolated) future is desirable or whether policy interventions are needed, and as a benchmark by which to compare the outcome of possible policy interventions, shocks, and economic restructuring. Several terms are used interchangeably: 'baseline scenario' (e.g. Dagoumas, 2014), 'reference case’ (e.g. Chaudry et al., 2015; McGlade et al., 2016), and 'business-as-usual' scenario. Höjer et al. (2008) suggest that 'reference case' be reserved for the type of scenario they term predictive. Barker et al. (2007) clearly distinguish between a reference case to establish a counterfactual history, and the base case as the fully operationalised solution. Alternatively, these terms can be avoided if this aids explanation and clarifies their purpose, for example Eyre and Baruah (2015) label one scenario as 'minimum (policy) intervention', and the Intergovernmental Panel on Climate Change (IPCC, 2015) use Representative Concentration Pathways which include trended data. Furthermore, the IPCC (2015) point out that using BAU does not make sense in a century-long projection.

Confusion arises when BAU is used to mean a reference case rather than the continuation of the current trends supported by data, for example scenarios for the Brazilian biodiesel industry (Dias et al., 2016), renewable energy globally (Sadorsky, 2011), the relative activity of different sectors in the UK economy (Shanmugalingam et al., 2010), and the UK low carbon transition (Oxford Economics, 2011). The term 'counterfactual' has also been used (DECC et al., 2015). Or in the case of describing scenarios for the circular economy Hobson and Lynch (2016) use BAU to mean everything other than circular economy regardless of any possible trajectories. In a similar vein, Strachan (2011) introduces 'business as unusual' (BAuU).

There is an outstanding problem with forecasting a macroeconomic BAU case relating to accounting for the physical capacity to deliver (economic) output at any point in time. Physical constraints exist in terms of the amount of infrastructure (FC), and the physical flows of goods and the construction process that determine the rate of change of the capacity of infrastructure (FCF). To be consistent with these physical constraints, an 'econo-physical' BAU case needs to take account of whole-system interactions such as economic demand, population, employment, housing, industry activity, transport, and energy demand and supply. To the best of our knowledge, no such econo-physical BAU has been modelled. To generate an econo-physical BAU case we need to understand the physical and underlying economic basis of GDP and GDP growth. GDP is an aggregate measure of economic volume flows which form part of national accounts (Lequiller and Blades,, 2014). The expenditure form of GDP plus imports corresponds to the sum of final demand in the form of final products. It is these final products that enable derivation of the GDP deflator so that economic volume flows, and thus GDP, can be expressed in real terms. GDP, and the national account data from which it is derived, has been shown to be a good predictor of energy demand in the medium-to-long term, while fuel price and population are poor predictors (Liao et al., 2016).

Using economic models without any physical constraints, many organisations forecast GDP growth for up to two years with Consensus Economics (2015) averaging 26 UK forecasters. Despite the short-term horizon, these forecasters have a poor record of predicting annual GDP prompting a performance evaluation by the Bank of England (2015). They assessed Bank forecasts to have over-estimated growth in 2008 by $9 \%$. However, they also observed that the accuracy of their forecasts compared favourably with private sector forecasters and other central banks, especially at the one-year time horizon. Alternative approaches (Keen, 1995, 2013), using system dynamics, are able to mimic observable macroeconomic behaviours. Purely economic models do not take account of changing efficiencies, which Ayres and Warr (2009) show to be important. They suggest that it is better to seek trends in multiple explainable and understood inputs and see how they interact rather than single outputs.

Subsequently in 2010, the UK Government set-up the Office for Budget Responsibility (OBR) to provide independent analysis of the public finances. Their estimation of GDP growth over 2015 to 2020 is about $2 \%$, but an $80 \%$ uncertainty band of $\pm 1.2 \%$ in 2015 increasing to $\pm 3 \%$ by 2020 (OBR, 2016). The OBR go on to discuss the key uncertainty of productivity stating that all forecasters need to decide what weight to place on recent performance. We will show (Section 2) that our method does not require us to make this choice. 
SH. Roberts, CJ. Axon, NH. Goddard, BD. Foran, \& BS. Warr (2019). Modelling socio-economic and energy data to generate business-as-usual scenarios for carbon emissions. J. Cleaner Production, 207, pp.980-997. https://doi.org/10.1016/j.jclepro.2018.10.029

\subsection{The Aims and Organisation of this Paper}

Our aim is to show how a physically plausible BAU case, which represents the observable operation of an economy, can be generated to give a defensible basis upon which to create econo-physically consistent projections (scenarios) using the novel 7see-GB model. We will then apply this new technique to a pertinent issue for developing an understanding of future UK carbon emissions.

The 7see data framework and model evolved whilst developing the UK case study. In this paper we present this case study in detail. In Section 2 we describe how the general principles of trending for 7see models are applied to actual country data so as to run the model beyond the historical period into the future. We show how a complete econo-physical scenario is built up where overall economic activity is linked into a target level of unemployment. In Section 3 we illustrate application of the methodology to a case study of the BAU scenario used in the UK Government's fifth carbon budget to 2035. This covers trending of both endogenous and exogenous coefficients and demand. We show what can be learnt from the case study model in Section 4 (Conclusions). We use three appendices to collate the detailed elements of the methodology.

\section{The Generalised Method for Trending BAU in a 7see-type Model}

The 7see analytical framework (Roberts et al., 2015) brings together official national accounts with physical and social datasets. The physical and social data used span energy, transport, housing, population, and employment. For economic data the 7see framework is fully aligned with the system of national accounts (SNA) (United Nations et al., 2009). The framework curates and maintains the time-series stocks and flows of the various datasets in a modular way, thus is able to retain each of their unique measurement unit and accounting requirements.

The 7see model (Roberts et al., 2016) operationalises this framework. The purpose of this approach is to express constraints between the component stocks and flows of the macroeconomy, for example, capital stocks and capital formation, specifically gross fixed capital formation, GFCF. A 7see-type model assumes that for each of the flows, their supply follows demand, but is constrained in the short-term by physical infrastructure or by their own demand for inputs needed to create output to satisfy demand. The 7see model does not use price. Final demand determines the supply by the larger industries of manufacturing, construction and services through the input-output relationship of intermediate consumption (IC). This structure forms a feedback loop which any model must mimic. However, those outputs are also constrained in the short-term by the level of fixed capital (FC) required to produce them. Final demand is mostly set exogenously in the model, though this can be constrained by linkage to indicators. Inputs are then determined from demand for outputs, via physical infrastructure. A 7see-type model captures this behaviour by allowing macroeconomic variables to evolve over time with feedback mechanisms. In this way, it is possible to explore the effect of policy choices under the assumption that efficient capital allocation methods are employed to effect those policies. In operationalising a 7see analytical framework, there is no reliance on optimisation as the core of the method. In contrast to most economic analyses which specify a rate of economic growth, the 7see approach treats economic growth as the combined outcome across all industries and thus the infrastructure foundations and required physical inputs.

The evolution of relationships between stocks and data flows in a 7see-type model are captured by timevarying coefficients (Roberts et al 2016). To regenerate historical stocks and flows, these coefficients are ratios linearly interpolated between annualised historical data. For the model to continue beyond the recent end the historical data period, we need to transition these coefficients smoothly to an analytical form. The interpretation of falling trends in coefficients of production would include improvements in efficiency through technological advance, automation, better organisation and up skilling. The interpretation of rising trends would be change to outsourcing, switch between inputs and consequences of national regulations, such as for safety measures, insurance cover or security checks. To extend from regeneration of historical data to modelling a BAU case, we have two key steps: 1) trending of coefficients to exploit historical data for insights into relationships for their evolution, and 2) defining a small and appropriate number of exogenous future trends and macro-level targets.

National economic output is determined by (long-lived) FC, so at the macro-scale an economy has momentum and takes time to change (has inertia). We characterise the well-understood relationships between FC and its outputs using coefficients. Like FC itself, many of these coefficients are static or change only slowly. We suggest that it is important to explore this characterisation as a robust way to understand econo-physical BAU scenarios. These coefficients capture fundamental aspects of systemic interaction and thus underpin the quality of the future scenario. 
SH. Roberts, CJ. Axon, NH. Goddard, BD. Foran, \& BS. Warr (2019). Modelling socio-economic and energy data to generate business-as-usual scenarios for carbon emissions. J. Cleaner Production, 207, pp.980-997. https://doi.org/10.1016/j.jclepro.2018.10.029

A key principle of a 7see-type model is that an economy is made up of types of infrastructure, each of which produce a unique output. A straightforward example of a unique output is electricity as supplied by the fleet of power generators. While the range of manufactured goods is very wide, we also refer to manufacturing as a unique output (of goods), as supplied from manufacturing industries and imports. Goods are treated only as a flow - there is no modelling of inventory. A 7see-type model then maintains separate accounts of different classes of unique outputs. We introduce the nomenclature of $F C$ for infrastructure and $p$ for the output it produces. For economic outputs that evolve in form as a consequence of IC, we designate by $p$ evolving through $q, r$ and $s$ to $f$. This view of infrastructure and outputs notes the following constraints:

- Each product output $p$ is unique and non-substitutable with other outputs $p$ in the short term.

- Product output $p$ requires $F C$ for its production, so FC determines supply.

- $F C$ requires the inflow fixed capital formation, $F C F$, for maintenance and growth.

- The total availability of FCF is in limited supply.

We define short-term non-substitutability as a shift from one type of supply to another needing investment in fixed capital. For example, a shift from gas to electricity for domestic heating will mean changing the equipment in many homes which would take years if not decades. In Table 1. we disaggregate an economy into six industries along with other types of stocks which we number by $j$ (Roberts et al., 2016).

\begin{tabular}{llll}
\hline $\boldsymbol{j}$ & Industry/stock & Fixed capital or stock & Product or flow \\
\hline 1 & agri & Agriculture, forestry and fishing & Agriculture, forestry and fishing products \\
2 & extr & Mining and quarrying & Fossil fuels, ores and minerals \\
3 & util & Supply of electricity, gas, water and & Electricity, gas and water \\
& & water remediation & \\
4 & manu & Manufacturing & Goods from manufacturing \\
5 & cnstr & Construction & Construction services \\
6 & serv LR & Service industry & Services (less rental) \\
7 & dwlg & Dwellings & Rental (actual and imputed) \\
8 & trans & Vehicles & Travel \\
\hline
\end{tabular}

Table 1. The six industries within a 7see-type model together with dwellings, rental and transport.

An issue with any model of this nature is distinguishing between endogenous and exogenous variables. Endogenous variables are where the model is justified as representing actual real-world relationships versus exogenous of true freedoms within the economy or aspects of the economy not covered by the model. We aim for a 7see model to be as endogenous as far as is reasonable. The need for calibration of the model is only for complex feedback of supply $r$ in three cases and positive feedback of investment. The dynamics of a 7see model consist of time-independent relationships mediated by time-dependent coefficients,

$$
p_{\text {model }}(t)=\operatorname{coef}_{\text {historical }}(t) F C_{\text {model }}(t)
$$

where,

$$
\operatorname{coef}_{\text {historical }}(t)=\frac{p_{\text {historical }}(t)}{F C_{\text {historical }}(t)} \text {. }
$$

As we continue the model beyond the end of the historical period, we need to change from coef historical $_{\text {to }}$ coef $f_{\text {trended }}$ in a smooth transition since for any scenario, we assume continuity of relationships between all parts of the economy.

We break down the process of setting up an econo-physical BAU scenario into three parts: trend coefficients that underlie relationships (section 2.1), trend the exogenous variables (section 2.2), and configure 
SH. Roberts, CJ. Axon, NH. Goddard, BD. Foran, \& BS. Warr (2019). Modelling socio-economic and energy data to generate business-as-usual scenarios for carbon emissions. J. Cleaner Production, 207, pp.980-997. https://doi.org/10.1016/j.jclepro.2018.10.029

overall economic activity (section 2.3). We are then in a position to run the model forward to the chosen end date and inspect the outcomes.

\subsection{Characterising the Underlying Trends in Relationships}

We are most interested in two principal features of the coefficients. First, that if a coefficient does not correlate with economic growth fluctuations, then it is likely to be a fundamental aspect that can be trended into the future, irrespective of economic booms and recessions. Second, that there is a smooth form over the historical period which would justify trending. Given that an economy is slowly varying, historical trends should be assessed over a period of about 20 years. This period is likely to include booms and recessions as well as evolution of interactions.

We divide coefficients into classes. The first involves stock variables in 7see which are unaffected by, or consumed in, the production process. For example, fixed capital FC (Appendix A). We also include housing stock under $d w \lg (j=7)$ and fleets of vehicles under trans $(j=8)$ (Appendix B).

For the first class, we consider production $p_{j}$ of industry $j$ as a function just of its fixed capital $F C_{j}$ according to time $u_{j}$. We index $p_{j}$ and $F C_{j}$ to $u_{j}=0$ representing the last year of the historical data as $p_{j}{ }^{\prime}$ and $F C_{j}{ }^{\prime}$. If there has been constant returns over the historical period, they are directly proportional, thus,

$$
p_{j}^{\prime}\left(u_{j}\right)=F C_{j}^{\prime}\left(u_{j}\right)
$$

In the example data in Fig. 2, $p$ ' and $F C^{\prime}$ ' change at different rates. We can express this departure from constant returns in the form of an output coefficient $O C_{j}^{\prime}\left(u_{j}\right)$ where,

$p_{j}{ }^{\prime}\left(u_{j}\right)=O C_{j}{ }^{\prime}\left(u_{j}\right) \cdot F C_{j}{ }^{\prime}\left(u_{j}\right)$

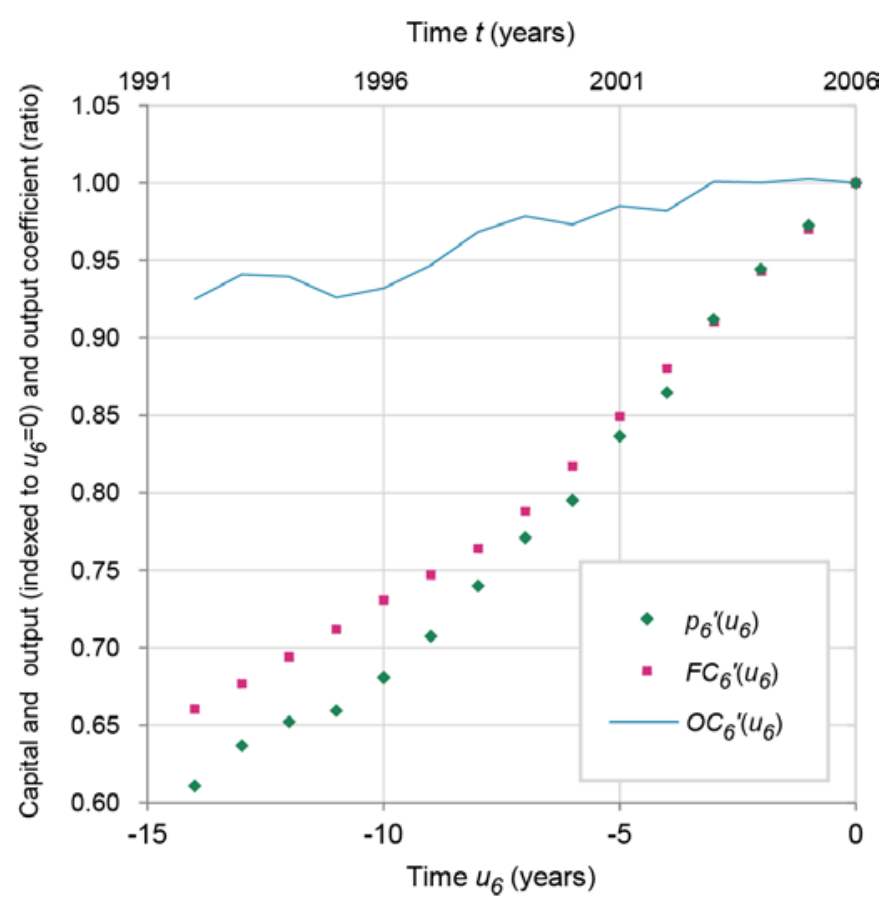

Figure 2. Example from $\operatorname{serv} L R(j=6)$ for the UK with $u_{6}=0$ (the indexing year) set to 2006 of indexed output $p_{6}$ ' and fixed capital $F C_{6}$ '. The difference in their rates of change is shown by the indexed output coefficient, OC, $_{6}$. Data source: ONS (2014a, 2015a). For FC pre-1997, data was provided by the ONS in 2010. 
SH. Roberts, CJ. Axon, NH. Goddard, BD. Foran, \& BS. Warr (2019). Modelling socio-economic and energy data to generate business-as-usual scenarios for carbon emissions. J. Cleaner Production, 207, pp.980-997. https://doi.org/10.1016/j.jclepro.2018.10.029

We identify trends in historical data by starting with the most recent, which we take as the most significant. The last year of historical data varies across our datasets. Often the most recent national accounts data from Supply and Use Tables can be three to four years old, while energy data two to three years old, and jobs data one to two years old. As a consequence, we are free to vary to which year $u_{j}=0$ corresponds for each coefficient to ensure that the most recent is the most significant.

For our second class of coefficients, we consider separately the relationship to production, $p_{j}$, of each input in turn. Examples are labour, $L_{j}$, and electricity, $G_{j}$, for industry $j$, indexed to $u_{i}=0$ as $L_{j}{ }^{\prime}$ and $G_{j}{ }^{\prime}$. Given that we take a demand-lead view, we set $L_{j}$ and $G_{j}$ as subjects. This means we are asking what level of jobs or electricity would be needed to achieve the level of production. For constant returns to scale,

$L_{j}{ }^{\prime}\left(u_{j}\right)=p_{j}{ }^{\prime}\left(u_{j}\right)$, and

$G_{j}^{\prime}\left(u_{j}\right)=p_{j}{ }^{\prime}\left(u_{j}\right)$

As in Eq. (2) we can introduce functions, which here we call production coefficients, to capture departure from constant returns in historical data,

$$
\begin{aligned}
& L_{j}{ }^{\prime}\left(u_{j}\right)=P C_{L j}{ }^{\prime}\left(u_{j}\right) \cdot p_{j}{ }^{\prime}\left(u_{j}\right), \text { and } \\
& G_{j}{ }^{\prime}\left(u_{j}\right)=P C_{G j}{ }^{\prime}\left(u_{j}\right) \cdot p_{j}{ }^{\prime}\left(u_{j}\right)
\end{aligned}
$$

Production coefficients, $P C_{L j}{ }^{\prime}\left(u_{j}\right)$ and $P C_{G j}{ }^{\prime}\left(u_{j}\right)$, describe how the intensities vary with time of each input needed per unit of output.

Our third class of coefficients cover the evolution of individual flows. For example, the pq coefficient is from industrial output categorised by industry to categorised by product, and the tax coefficient is for production from net to gross of tax on products. Other coefficients are detailed in Appendices A and B.

The coefficients we have introduced so far relate FC to output (class 1), output to inputs needed for production (class 2) and the evolution of flows (class 3). We now generalise these to all types of physical assets included in a 7see model, such as dwellings and road vehicles. We examine carefully the choice of proxy to quantify the physical assets since this has a direct impact on the quality of coefficient trending. See Appendix A for all coefficients needed for each 7see high-level industry and Appendix B for other coefficients.

For all coefficients, we propose a family of functional forms (Fig. 3). We suggest there are four members of this family:
A. Decay down to a horizontal asymptote
B. Constant
C. Decay up to a horizontal asymptote
D. Linear increase

Taking an example $P C^{\prime}(u)$, three of these forms, A-C, can be expressed in the general form,

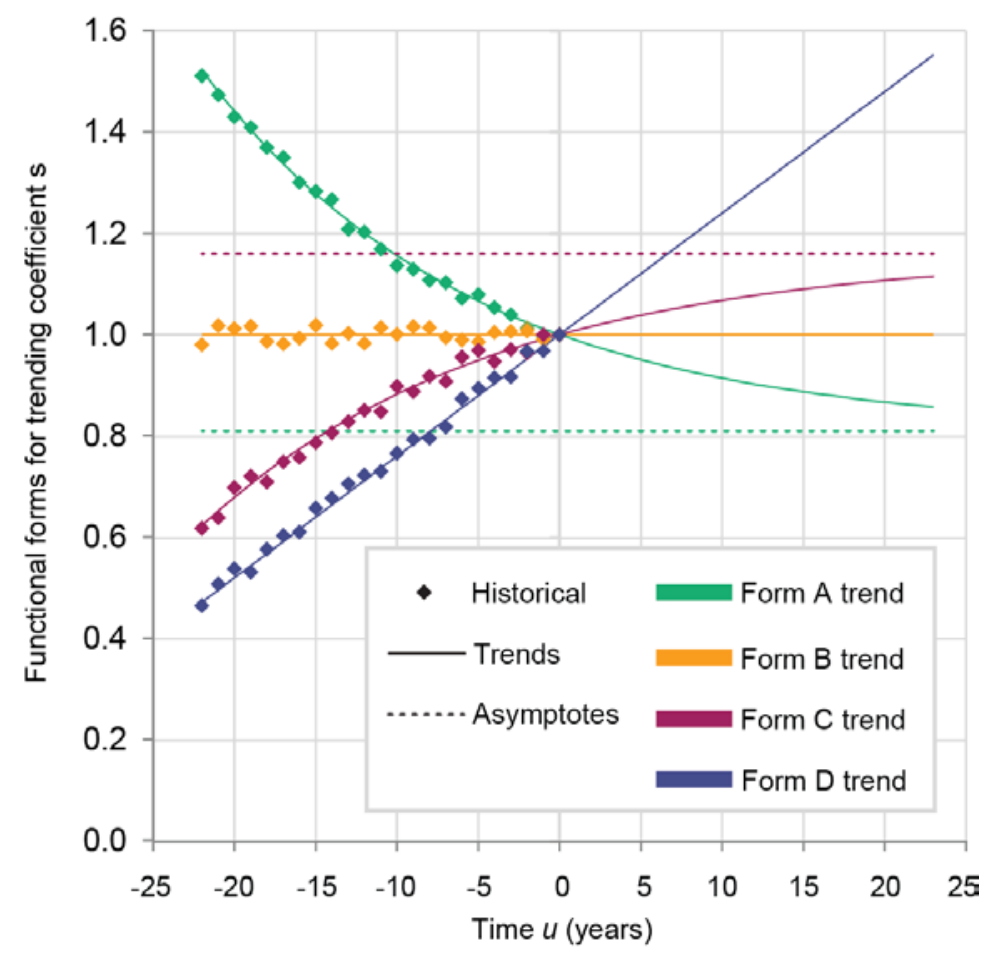

Figure 3. Illustration of four functional forms for trending of indexed coefficients: form A of decay down to an asymptote; form B of a constant; form C of decay up to an asymptote; form D of a linear increase. Time $u$ is with respect to the most recent historical data. Synthesised data shown here for the historical period using random numbers around the mathematical form as a visual aid only. 
SH. Roberts, CJ. Axon, NH. Goddard, BD. Foran, \& BS. Warr (2019). Modelling socio-economic and energy data to generate business-as-usual scenarios for carbon emissions. J. Cleaner Production, 207, pp.980-997. https://doi.org/10.1016/j.jclepro.2018.10.029

$$
P C^{\prime}(u)=(1-Z) u^{-T F}+Z
$$

where $Z$ is the horizontal asymptote and $T F$ is the time factor of the decay. In the special case of form $\mathrm{B}, T F$ is zero. For form $D$ of linear increase,

$$
P C^{\prime}(u)=(L R \cdot u)+1
$$

where $L R$ is the linear rate.

For each product or input, we inspect the historical data and select the most appropriate trending form from A-D. For the decay forms of A and C, we can use a double regression to find pairs of values of $T F$ and $Z$ for best fit. Where the historical data does not fit with any of the trending forms A-D we might consider making a country comparison to indicate a typical behaviour. Otherwise we first trend these as a constant, form B, and in repeated runs of the model do a sensitivity analysis applying slopes to the trend that encompass the historical data so that we can qualify our average scenario according to the uncertainty of these trends.

We are using these observable trends as a starting point to generate a first-order econo-physical BAU scenario. Once the significant contributors to the first BAU scenario can be identified, we might then choose to delve back in for a targeted examination of the coefficient trends for these significant contributors.

Historical data are scattered about the trend line. The most recent historical data point is unlikely to be on the trend line yet we do not want an abrupt jump from this point to the post-historical period using the calculated trended values. Irrespective of the trending forms A-D, we make a smooth linear transition over three years from the last historical value onto the trend line.

\subsection{Characterising Trends of the Exogenous Variables}

Where control of an asset is not endogenous through feedback to meet demand, the control is exogenous. These are usually handled by trending the historical behaviour unless there is other information available. In addition, we perform the following sense-checks of the scenario:

- That unemployment never goes below zero.

- That the number of dwellings is always greater than the number of households.

- That whichever generation technology is used to balance electricity demand, the capacity does not go below zero (combined cycle gas turbine (CCGT) generation is used for the UK).

- If renewable electricity generation increases to more than about 30\% (APS, 2010), then to address the issues of intermittency (reducing the load factors) CCGT makes up any short-term generation shortfall.

- The size of non-trade contributors to balance of payments in case some contributors need readjustment.

\subsection{Configuring Overall Economic Activity}

A 7see-type model is demand-lead so we need to consider carefully how we trend final demand since it dictates overall economic activity. We divide final demand into GFCF, actual final consumption (AFC) and exports. GFCF is endogenous in a 7see-type model and we trend exports according to historical behaviour. Thus we remain with how to determine future AFC and its principal components of goods and services.

AFC affects the overall level of economic activity, and its behaviour reflects the big challenges for governments, central banks and others seeking to control and stimulate an economy. A simple criterion for jobs might be that unemployment can never go below zero - the economically active population must be larger than the requirement for jobs - but in practice we do not find that this is a limit for plausible future scenarios in the UK model.

The level of unemployment has such an impact on society and takes such a high profile in national political and economic policies that we use this to determine these otherwise exogenous variables. The level of employment is influenced most by the size of the largest employer. By this we mean that we set a target unemployment level for the future projected period and iterate consumer demand of AFC of services so as to meet this target unemployment value (see Fig. 4). Antonelli and Fassio (2014) note in advanced countries the decline of the role of the manufacturing industry and the emergence of a strong knowledge intensive business service sector. We trend AFC for goods based on recent historical behaviour since we find that for the UK this has been constant. 
SH. Roberts, CJ. Axon, NH. Goddard, BD. Foran, \& BS. Warr (2019). Modelling socio-economic and energy data to generate business-as-usual scenarios for carbon emissions. J. Cleaner Production, 207, pp.980-997. https://doi.org/10.1016/j.jclepro.2018.10.029

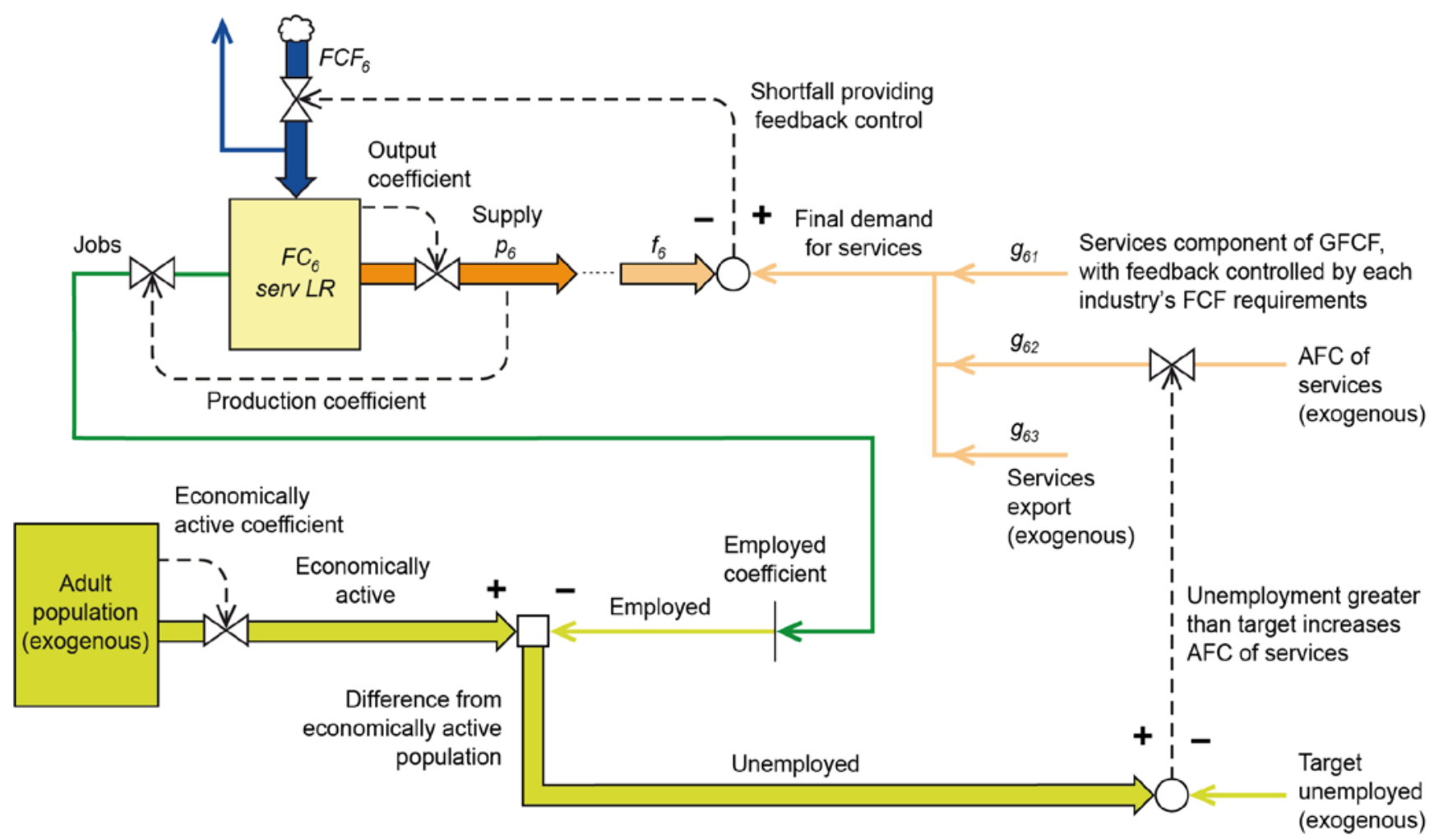

Figure 4. Determination of projected AFC for services by feedback on a target level of unemployment. This is a selfbalancing loop.

We explain the schematic of Fig. 4 by starting at $F C_{6}$, the fixed capital of the service industry, and following all the connected arrows, which take us in an anti-clockwise direction. The level of $F C_{6}$ determines its output $p_{6}$ according to the output coefficient and this output sets demand by the services industry for the level of jobs needed according to the production coefficient. Jobs data is converted to people-based employed, so the employed coefficient allows for some people having more than one job. Meanwhile we derive the economically active population from the total adult population. Unemployed is defined as the difference between the economically active available and the demand for employed. Given that we set a target level of unemployed, we compare the actual level to this target. Where it is higher, we need to increase demand for services and we change this level of demand from the previous time step. This particular step within our model encapsulates many steps within the economy in which government and central bank policies seek to work together to stimulate demand-lead activity. Continuing around, higher final demand for services results in the model with investment (FCF) to increase $F C_{6}$.

The level of unemployment in the model is critically dependent on, (a) the downward trend of jobs needed per unit output of services (Fig. 7), and (b) growth in consumer demand for services and government delivery of services, which together increase the number of jobs. Taking the UK historical data as example, one interpretation of the historical period 1990-2013 would be that the economy has managed to expand final demand for services sufficiently to keep unemployment in check. Population is shown in Fig. 4 on the left where it impacts economically active.

We iterate demand for services to achieve a constant unemployment rate of around $6 \%{ }^{2}$ by 2030 . In practice we find that because the unemployment rate is a small number that is dominated by the difference between two large numbers (population and jobs), this adjustment requires only very small changes in the demand for services. The mechanism is for actual final consumption of services at time $t+1, A F C_{6}(t+1)$, is

${ }^{2}$ High unemployment is bad for individuals' self-esteem and personal health as well as leading to poverty and social unrest. This is balanced against an optimal or natural unemployment rate for an economy in which people are available for hire (without poaching from existing employers) and inflation due to wage pressure is minimised. 
SH. Roberts, CJ. Axon, NH. Goddard, BD. Foran, \& BS. Warr (2019). Modelling socio-economic and energy data to generate business-as-usual scenarios for carbon emissions. J. Cleaner Production, 207, pp.980-997. https://doi.org/10.1016/j.jclepro.2018.10.029

$$
A F C_{6}(t+1)=A F C_{6}(t)+\text { increment }
$$

Where

increment $=($ unemployed - target_unemployed $) \cdot$ gain

is constrained to \pm increment_limit.

The model transitions from the historical phase of AFC with its resulting unemployment to the future phase when these are swapped and target unemployment drives AFC. We configure this swap by starting with control of unemployment set to whatever its value is at the last historical year. We smoothly transition the controlling value of unemployment to the long-term target over three years. The values of gain and increment_limit are calibrated for a smooth approach to the target unemployed value within a few years.

The purpose of running a model is to reveal indicators of interest, which can only be those endogenous to the model. For instance if unemployment is set, as in Fig. 4, this will be exogenous while the economic growth resulting will be endogenous. On the other hand, if final demand were to be iterated to achieve some predetermined economic growth (exogenous), then unemployment would be endogenous. In Appendix C we show how to use the 7see approach to attribute final output to particular inputs by following back through IC.

\section{Case study: the UK}

We demonstrate application of our methodology by creating an econo-physical BAU scenario for the UK and compare it to Cambridge Econometrics (2015) modelled $\mathrm{CO}_{2}$ emissions for the UK economy between 20002035 (on behalf of the Committee on Climate Change). Our case study starts in 1990 with the historical data (to 2013-2015 depending on availability) reported in Roberts et al. (2015). We have validated the use of the three larger industries (Roberts et al., 2015), which we control using feedback to FC to meet final demand. We use CCGT to balance demand for electricity.

\subsection{Trending coefficients}

We show examples of how the four functional forms of trending of indexed coefficients can be applied to real data along with a continuous functional form of a coefficient, as used in the model (Fig. 5).

The decay down to an asymptote is shown for the jobs coefficient of manu (Fig. 5(a)). We note steep declines after the recessions of 1990-1991 and 2008-2009 (Hills et al., 2010). We suggest manufacturers focused on reducing labour costs by quick measures to implement, such as organisation change and redefining roles. By considering data over 22 years we note that gentler declines between the recessions give rise to an overall decaying trend. This long-term behaviour is indicative of automation from replacing old machinery (plant) with new, as well as technological advance and innovation. Given the strong long-term trend, we pin our extrapolation to 2012 and its data point (on this trend), thus giving less weight to the 2013 data point which departs (below).

Fig. 5(a) also shows our selection of decay up to an asymptote for imports coefficient of goods by manu. We note a gentle growing trend to 1997 which transitions to an acceleration. Relevant influences might be Chinese exports increasing rapidly from 2001 (Kang and Lee, 2007; Yang, 2016) as a key component of globalisation. We suggest the trend is flattening out as UK manufacturers became more efficient and internationally competitive as they outsourced lower value activities in the value chain to emerging economies (OECD, 2007). Companies have also shifted to 'servitization' - products combined with associate services (BIS, 2010). The absolute value of the imports coefficient in 2012 of 3.1 approaches an asymptote of 4.0 i.e. imports are four times greater than indigenous manufactured goods.

Our selection of constant for the economically active coefficient is shown in Fig. 5(b). The economically inactive consists of those unable to work, sick, looking after family or home, and students. When taken as a proportion of the population of working age, this has been declining over this period (ONS, 2015b). At the same time, the retired population has been rising as people live longer. Our coefficient is of the entire adult population and it would appear that these offset each other giving rise to the constant trend we see, corresponding to an absolute value of $63 \%$ of those of working age. 
SH. Roberts, CJ. Axon, NH. Goddard, BD. Foran, \& BS. Warr (2019). Modelling socio-economic and energy data to generate business-as-usual scenarios for carbon emissions. J. Cleaner Production, 207, pp.980-997. https://doi.org/10.1016/j.jclepro.2018.10.029

A linear increase is shown in Fig. 5(c) for imports coefficient of services by serv $L R$. In absolute terms, the coefficient is rising from 0.07 in 1990 to 0.12 in 2013. There is no sign in the data of levelling out so we suggest a continuing linear rise. This trend is justified because of globalisation spreading progressively to services together with digitisation and the web enabling more scope to trade services (OECD, 2007).

a
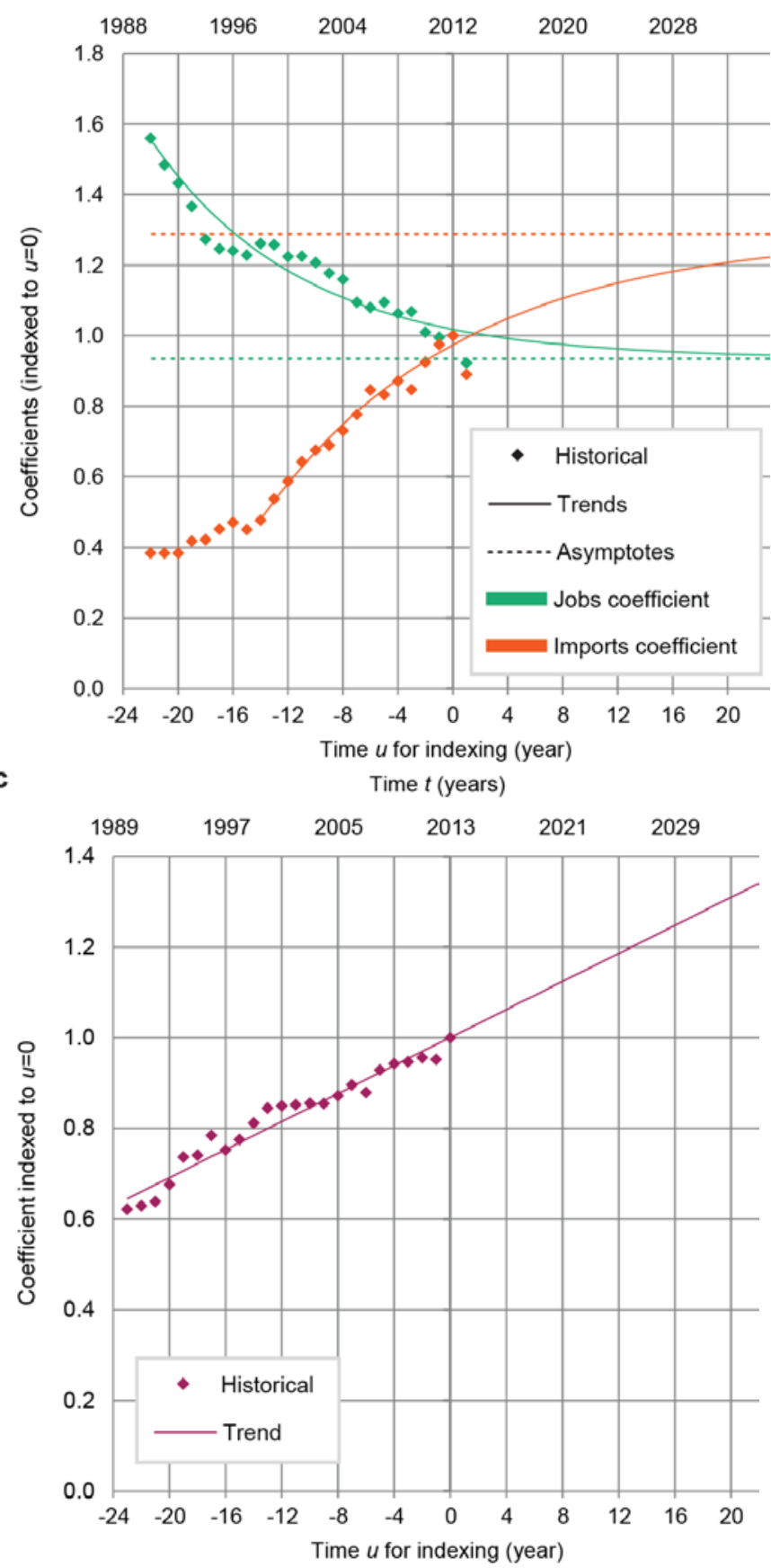

b

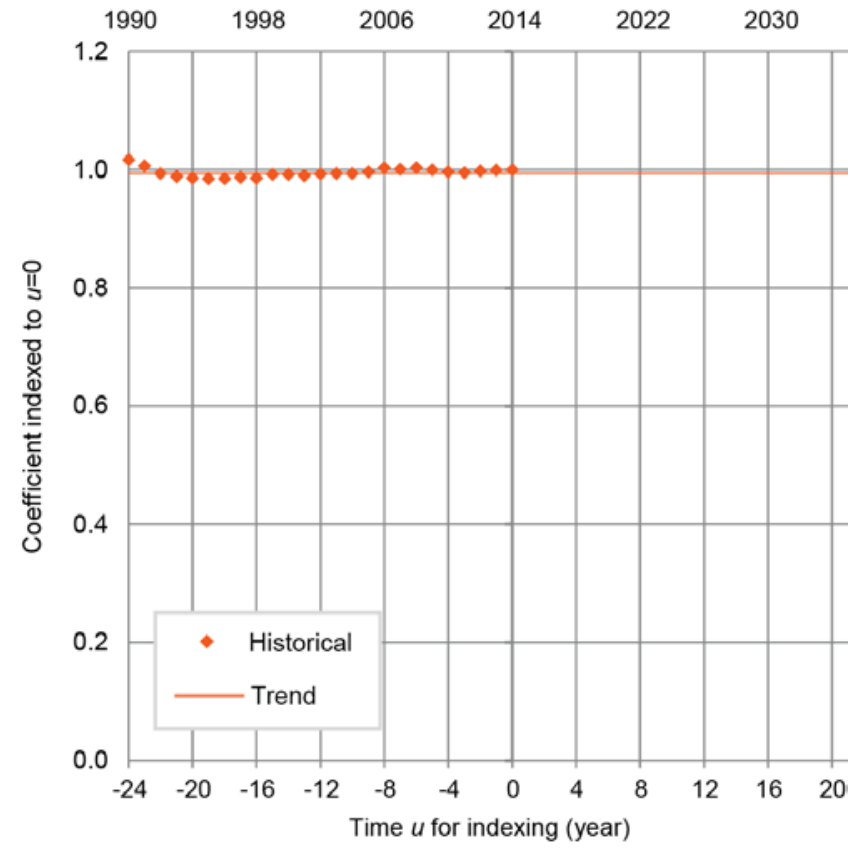

Figure 5. Examples from our UK case study of functional forms for trending of indexed coefficients. (a) jobs coefficient of manu $(j=4)$ for form A, and imports coefficient of goods by manu for form C, both indexed to $2012\left(u_{4}=0\right)$. (b) proportion of active population for form $\mathrm{B}$, indexed to $2014\left(u_{9}=0\right)$. (c) imports coefficient for services by serv $L R$ with form $\mathrm{D}$, indexed to $2013\left(u_{6}=0\right)$. Data source: ONS (2015a, 2015b, 2016). 
SH. Roberts, CJ. Axon, NH. Goddard, BD. Foran, \& BS. Warr (2019). Modelling socio-economic and energy data to generate business-as-usual scenarios for carbon emissions. J. Cleaner Production, 207, pp.980-997. https://doi.org/10.1016/j.jclepro.2018.10.029

The 2007/8 financial crash is shown in Fig. 6 as a drop in GDP growth to $-0.5 \%$ in 2008 and $-4.2 \%$ in 2009. By inspection, none of the particular coefficients in Fig. 5 appear to have been affected by the crash. The jobs production coefficient for service industry (less rental) is not so straightforward to trend, and needs close scrutiny since it has an impact on overall economic growth. Fig. 7(a) shows historical data for the indexed jobs production coefficient of serv LR. We note a clear trend over 1992-2008 after which the trend plateaued. We suggest that during the financial crisis of 2008 employees being willing to remain in post, but for fewer weekly hours, was a contributory factor in shift of the trend. In Fig. 7(b) we compare behaviour of five economies: developing, developed, OECD, and non-OECD. Pre-2008, the UK behaviour is very similar to Australia and the USA, all showing the same downward decay, while Taiwan and Colombia show steeper declines. Post-2008, only the curve for the USA appears unaffected continuing down while the other countries show varying degrees of slowed decline. Colombia is most similar to the UK of rising to a plateau. This country comparison shows that the behaviour we observe for the UK is typical.

We note significant and relevant similarities to the indexed jobs production coefficient of manu in Fig. 5(a) where this has a plateau over 1994-1999 before resuming the long-term downward trend over the full historical period. For both serv $L R$ and manu, we associate the downward trends to automation, which we suggest for serv $L R$ is likely to resume. Therefore in the case of serv $L R$ we extrapolate by resuming the same trend but offset to 2015, as in Fig. 7(c) upper line.

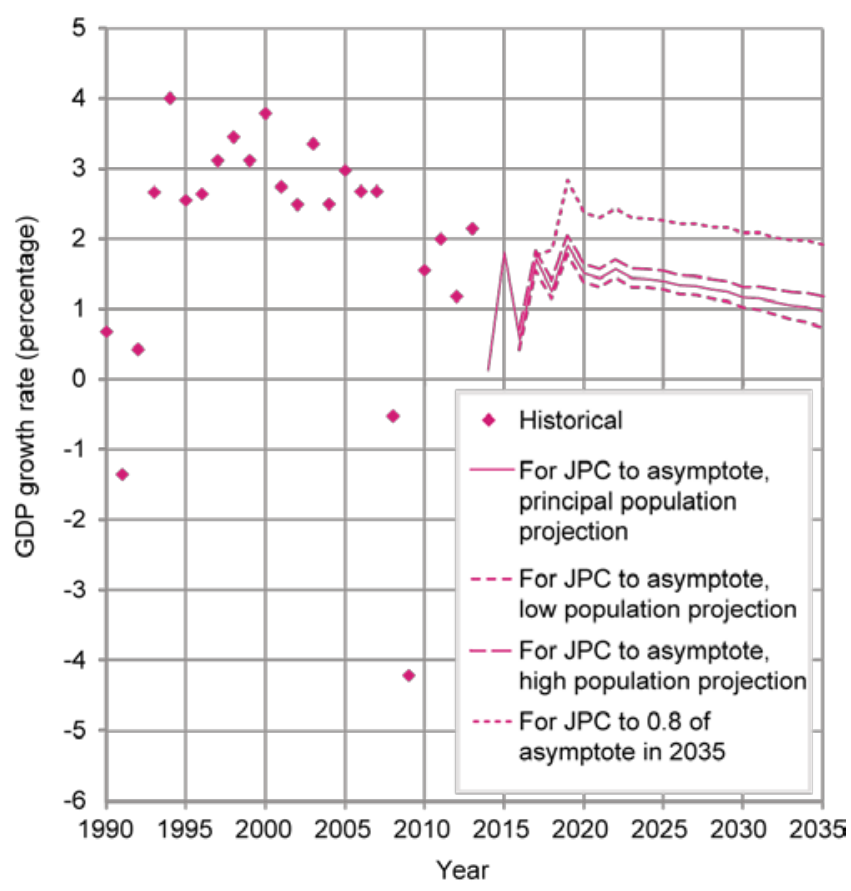

Figure 6. Economic growth showing historical data and trending from two extrapolations of jobs production coefficient (JPC) of serv LR to asymptote along with high and low population projections. Data source: ONS (2015a). 
SH. Roberts, CJ. Axon, NH. Goddard, BD. Foran, \& BS. Warr (2019). Modelling socio-economic and energy data to generate business-as-usual scenarios for carbon emissions. J. Cleaner Production, 207, pp.980-997. https://doi.org/10.1016/j.jclepro.2018.10.029
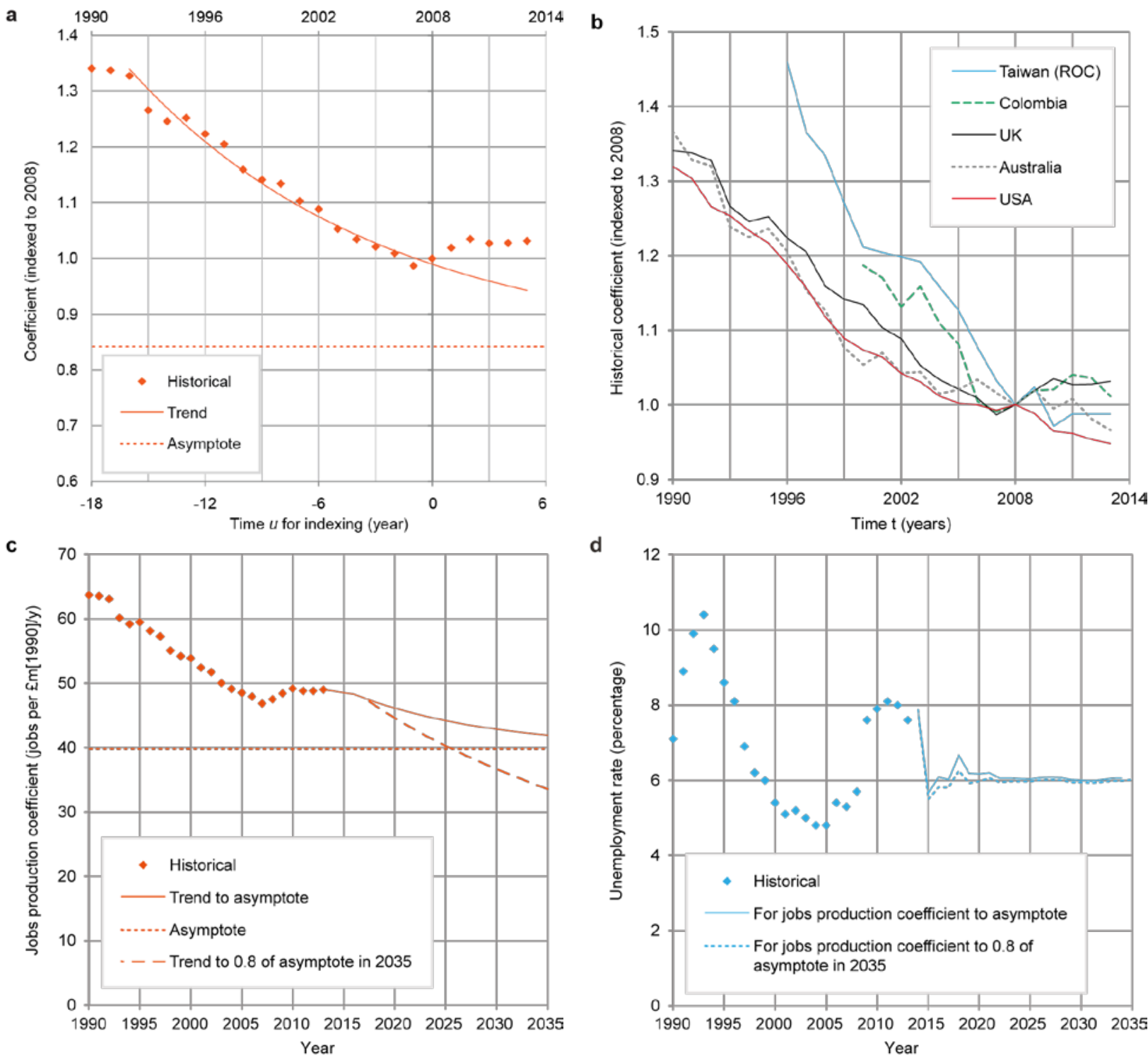

Figure 7. Trending of the jobs production coefficient of serv $L R$ and unemployment rate. (a) historical data for jobs production coefficient indexed to $u=0$ corresponding to 2008 with decay trend to an asymptote fitted to $u$ over -16 to 0 (the period 1992-2008). (b) historical data for jobs production coefficient of several countries indexed to 2008. (c) trending of jobs production coefficient with a steeper version to achieve a higher economic growth. (d) unemployment for two extrapolations of jobs production coefficient of serv LR. Data sources: ABS (2017a, 2017b), BEA (2017a, 2017b, 2017c), BLS (2017), DANE (2017a, 2017b, 2017c, 2017d), DGBAS (2017a, 2017b) ONS (2015a, 2015b, 2016).

\subsection{Unemployment and Economic Growth}

For the loop in Fig. 4, we take 6\% unemployment as the target level for the UK (Fig. 7(d)). An unemployment rate greater than $6 \%$ is generally accepted as the point at which central bankers consider making interventions (Federal Open Market Committee, 2012; Notton, 2016). The Cambridge Econometrics model does not seek to achieve some predetermined level of unemployment. Instead the level of unemployment is one of the factors that determines wage rates which in turn determine employment. Each year is solved by iteration such that demand is met. If unemployment goes to zero, the iteration does not converge (Cambridge Econometrics, 2014).

An important strength of the 7see methodology is that economic growth is not assumed or set, but is an emergent property. In contrast, many models set or assume a level of annual economic growth. Cambridge Econometrics (2015) examine a 20-year rolling average growth rate. For GDP they identify a central value of 
SH. Roberts, CJ. Axon, NH. Goddard, BD. Foran, \& BS. Warr (2019). Modelling socio-economic and energy data to generate business-as-usual scenarios for carbon emissions. J. Cleaner Production, 207, pp.980-997. https://doi.org/10.1016/j.jclepro.2018.10.029

2.3\%. Instead we focus on its indirect control. Upon generating our econo-physical BAU scenario, we find it manifests an annual economic growth of $2 \%$ falling to $1 \%$ (Fig. 6, lower curve). We consider this to be a defensible figure, although the OECD (2014) long-term forecast is in the range $2.5 \%$ to $3.0 \%$.

For comparability with Cambridge Econometrics, we explored changes in the trending of the jobs production coefficient since it has a strong influence on the annual growth rate. We can achieve $2.3 \%$ at 2025 , mid-way through our scenario period, as in Fig. 6 upper curve by increasing the downward slope in Fig. 7(c).

Since our choice of trending the jobs production coefficient of services is based on historical behaviour over 1992-2008, we examine this more closely by disaggregating industries with our grouping for serv $L R$ in case they show potential for future decline. Fig. 8 shows six industries for both jobs production coefficient and total jobs. The three largest industries have very similar behaviour, so are clustered around the industry-wide average. 'Financial, insurance and estate, K-L' (with reference to ISIC sections) exhibit a drop over 2002-2007 but rising over 2007-2010 as a consequence of the financial crisis. Only 'Other services, R-T' has shown a consistent decline. We note that 'Information and communication, $\mathrm{J}$ ' is much lower than the others owing to a high infrastructure content needed for this service. Thus, we suggest that extrapolation of the jobs production coefficient for serv $L R$ cannot decrease at the necessary rate to support using an annual economic growth rate of $2.3 \%$. The loop for serv $L R$ in Fig. 4 is also affected by population. We explore variation of the adult population using the range from modelling by the ONS (2016).
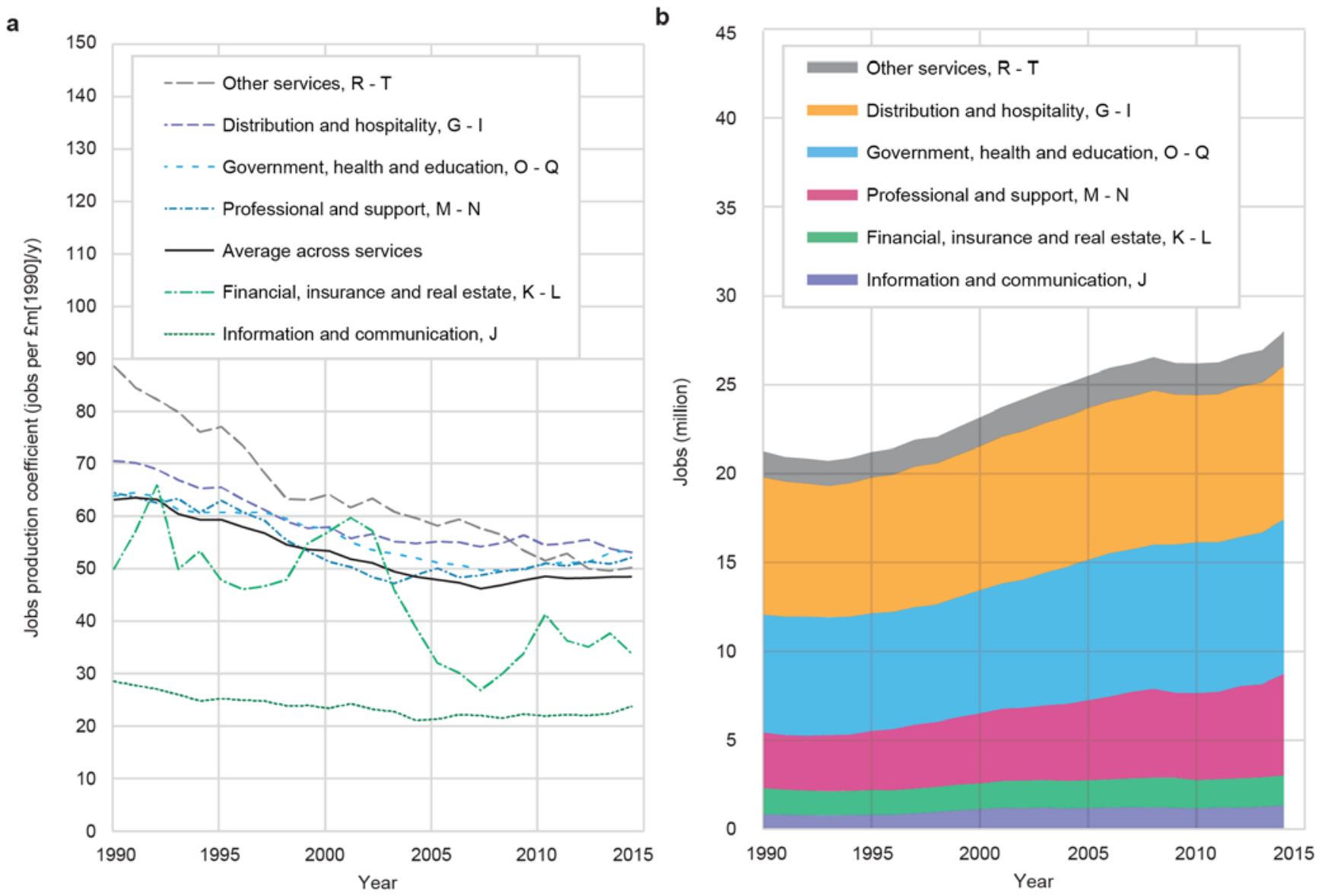

Figure 8. Disaggregation of serv $L R$ by ISIC section. (a) jobs coefficient. (b) jobs in each sub-industry of serv $L R$. 'Other services, R-T' divide almost equally into 'Arts, entertainment and recreation' (R) and 'Other service activities' (S) with only 3\% as ‘Private households’ (T). Data source: ONS (2015a, 2016). 
SH. Roberts, CJ. Axon, NH. Goddard, BD. Foran, \& BS. Warr (2019). Modelling socio-economic and energy data to generate business-as-usual scenarios for carbon emissions. J. Cleaner Production, 207, pp.980-997. https://doi.org/10.1016/j.jclepro.2018.10.029

\subsection{Carbon Dioxide Emissions}

From curating flows of fossil fuels used (combusted) within the economy, we convert each to $\mathrm{CO}_{2}$ emissions derived from their $\mathrm{CO}_{2}$ emission intensities (BEIS, 2016, 2017), then summing these for the economy-wide emissions. We bring together the various influences on our econo-physical BAU scenario in a set of $\mathrm{CO}_{2}$ emissions curves in Fig. 9. Comparing 7see to Cambridge Econometrics (2015) over the historical period 20002013, 7see is consistently lower by $20 \mathrm{MtCO}_{2} / \mathrm{y}$, or $4 \%$ in the average of $500 \mathrm{MtCO} / \mathrm{y}$. This offset can be accounted for by choice of different values of $\mathrm{MtCO}_{2} / \mathrm{PJ}$ intensity for combustion of coal and petroleum products. Cambridge Econometrics note that their emissions projections are at variance with others, mainly due to not estimating process emissions and using different carbon intensity values. Our work shows that these subtleties make a significant difference.

Where we use an extrapolation of the jobs production coefficient for serv $L R$ to match Cambridge Econometrics' growth, this same offset is apparent for $\mathrm{CO}_{2}$ emissions. Where we use our original extrapolation of the jobs production coefficient for serv $L R$, our $\mathrm{CO}_{2}$ emissions are much lower. Figure 8 also shows the sensitivity to the projection of population by the ONS, where the variation by 2035 is only $\pm 5 \mathrm{MtCO} 2 / \mathrm{y}$.

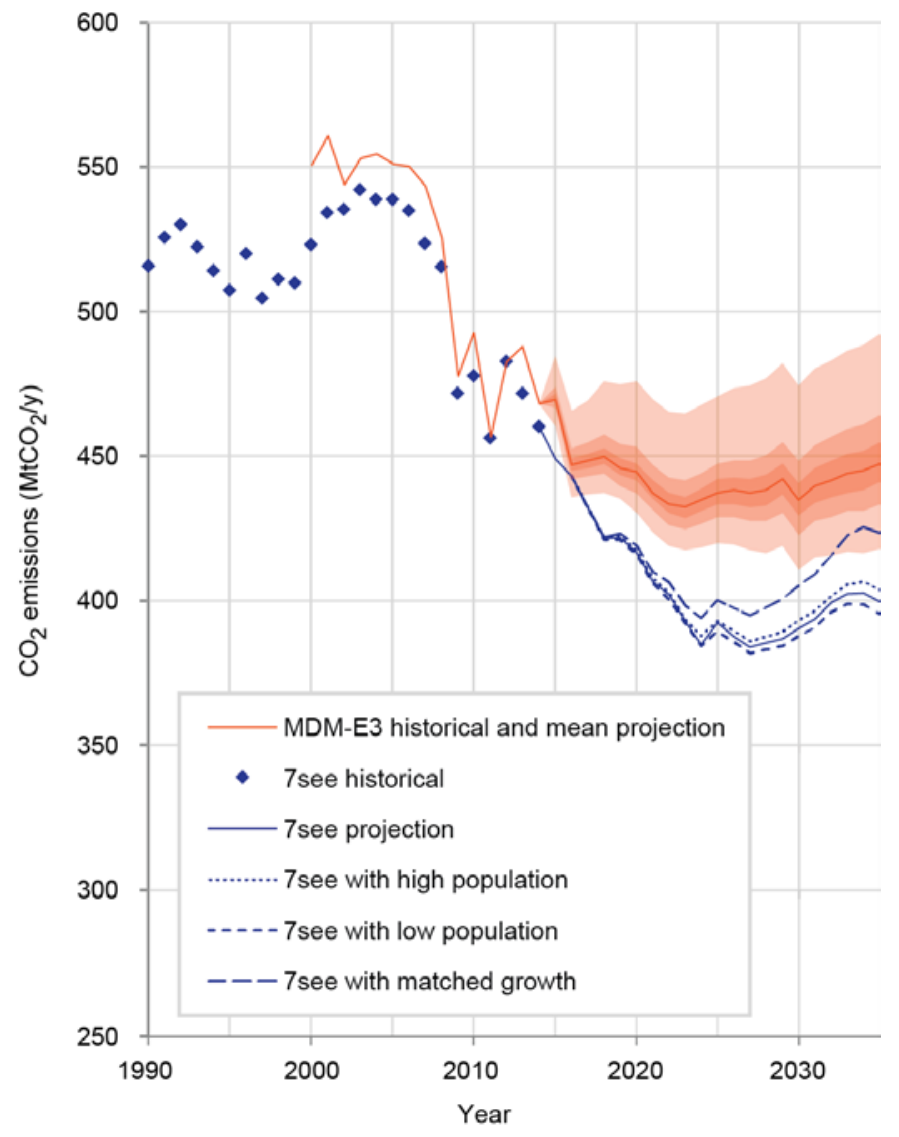

Figure 9 Historical and projected $\mathrm{CO}_{2}$ emissions according to the econo-physical BAU scenarios of 7see and CE (Fig. 1). The 7see scenarios are for inherent growth, high population projection, low population projection and a GDP growth of 2.3\% equivalent to Cambridge Econometrics'. 
SH. Roberts, CJ. Axon, NH. Goddard, BD. Foran, \& BS. Warr (2019). Modelling socio-economic and energy data to generate business-as-usual scenarios for carbon emissions. J. Cleaner Production, 207, pp.980-997. https://doi.org/10.1016/j.jclepro.2018.10.029

\section{Conclusions}

In scenario modelling it is convenient to use a reference case by which to compare the newly generated scenarios. Whilst this approach has it's merits, these reference scenarios are not usually an econo-physical BAU. Generating an econo-physical BAU scenario is not a task to which most economic or energy systems models are well-suited, or capable of at all.

The 7see model can be used to derive the intensity of any given input within final demand. For example, $\mathrm{CO}_{2}$ emissions from domestic sources or jobs per unit of final goods or services. This is sometimes known as its footprint (excluding emission embodied in imports). This methodology works back through IC presuming linearity in how inputs are apportioned, which we show using matrix analysis.

We have shown how physically plausible BAU scenarios can be developed by examining the historical behaviour of coefficients which manifest the relationship between components of an economy. We project these coefficients by putting weight on the most recent historical data and trending according to one of four functional forms: two linear and two asymptotic. We propose that macro-level demand for the actual final consumption of services can be considered as an outcome of economy-wide policies and behaviour focused on a target level of unemployment, thus making GDP growth endogenous. Our physically plausible BAU scenarios depend on only a small number of exogenous variables.

We have demonstrated the 'trendability' of coefficients in our case-study where many coefficients show well-established historical behaviour independent of economic booms and recessions. We have found that coefficients justify extrapolation according to our four functional forms, thus substantiating our econo-physical BAU scenario. We have explained the behaviour of coefficients for jobs in manufacturing, imports of goods and services, and the economically active proportion of the adult population. In some cases where horizontal asymptotes are approached, the value of the asymptotes suggests limits for how these relationships will evolve over time.

One exception to extrapolation according to our functional forms is the jobs coefficient of the service industry (the inverse of labour productivity) whose switch from exponential decay to constant coincides with the 2008 financial crisis. We show by comparison to four other economies that this behaviour is typical. Following the historical behaviour observed for jobs in manufacturing, we base our econo-physical BAU scenario on the jobs coefficient of the service industry resuming a downward trend to a horizontal asymptote. The consequence of this is that we manifest a GDP growth of $2 \%$ falling to $1 \%$. We find that $\mathrm{CO}_{2}$ emissions continue their historical fall reaching $390 \mathrm{MtCO}_{2} / \mathrm{y}$ in 2027 before rising to $400 \mathrm{MtCO}_{2} / \mathrm{y}$. We have tested sensitivity of these emissions for our exogenous input of adult population and found that by 2035 while the ONS high and low estimates for adult population vary by $\pm 3.8 \%$, emissions vary by $\pm 1.0 \%$.

Our case study compares $\mathrm{CO}_{2}$ emissions to the BAU projections of the UK fifth carbon budget commissioned by the Climate Change Committee from Cambridge Econometrics using their MDM-E3 model. Our historical values are consistently lower by $20 \mathrm{MtCO}_{2} / \mathrm{y}$, or $4 \%$, which we account for by choice of different values of $\mathrm{MtCO}_{2} / \mathrm{PJ}$ intensity for combustion of coal and petroleum products. Cambridge Econometrics base their BAU scenario on a GDP growth of 2.3\% derived from a historical 20-year rolling average. For the purpose of comparability, we steepen our decline in the jobs coefficient of services so as to match their $2.3 \%$ growth at 2025. We have found a good match of our emissions projections for BAU since while our difference of emissions increases to around $35 \mathrm{MtCO}_{2} / \mathrm{y}$ over 2020-2030, it drops back below $20 \mathrm{MtCO}_{2} / \mathrm{y}$ of the historical offset over 2030-35.

We have examined the plausibility of projecting a steep decline in the jobs coefficient of services for a $2.3 \%$ growth by disaggregating into six types of service. Only ISIC sections R-T, including arts, entertainment and recreation, show a decline that could continue, but they cover only $7 \%$ of employment in the service industry. Thus we find that maintaining 2.3\% growth of our comparator BAU scenario is not substantiated when based on historical behaviour of the jobs coefficient rather than trending the growth indicator itself.

A limitation of our approach is that we assume a well-functioning economy following well-behaved relationships (time-varying co-efficients in our terms) captured by historical data (a reasonable assumption for the UK). A single coefficient is not able to distinguish between multiple effects, such as any departure from constant returns to scale, operational improvements, technological change or replacement of old capital with new. We mitigate this limitation by using multiple time-varying co-efficients, though we appreciate that it may not be possible to create a plausible model of the economy of a nation undergoing severe political turmoil. Given that GDP is accepted as an indicator of economic activity and GDP is a summation of economic volume flows 
SH. Roberts, CJ. Axon, NH. Goddard, BD. Foran, \& BS. Warr (2019). Modelling socio-economic and energy data to generate business-as-usual scenarios for carbon emissions. J. Cleaner Production, 207, pp.980-997. https://doi.org/10.1016/j.jclepro.2018.10.029

with no referencing to pricing, our approach is rooted in economic reality, but what our approach is unsuitable for is modelling the effects of subsidies.

Our case study suggests that the sensitivity analysis of the CCC BAU scenarios under-estimates $\mathrm{CO}_{2}$ emissions reduction which may be possible in the UK's fifth carbon budget. The implications fall into three main areas: employment, economic growth, and GHG emissions. Support for continued growth of actual final consumption of services (consumer demand) will be essential to maintain employment. The service industry will need to grow across all its types, not just in the financial industries. Other policies predicated on a level of growth above $2 \%$ might need modifying in the light of a likely trend of growth downwards to $1 \%$. While the UK economy can take some comfort from continued falling domestic emissions, consideration of actions to pre-empt the projected $\mathrm{CO}_{2}$ emissions rise after 2025 need to be made. A 7see model helps policymakers to understand the component trends which contribute to the total emissions envelope. We have shown how our method of trending coefficients, in the case of jobs coefficient of services, is transferable to other economies. 
SH. Roberts, CJ. Axon, NH. Goddard, BD. Foran, \& BS. Warr (2019). Modelling socio-economic and energy data to generate business-as-usual scenarios for carbon emissions. J. Cleaner Production, 207, pp.980-997. https://doi.org/10.1016/j.jclepro.2018.10.029

\section{References}

Antonelli, C., Fassio, C., 2014. The economics of the light economy. Technological Forecasting and Social Change 87, 89107. doi:10.1016/j.techfore.2013.11.006

ABS, 2017a. Australian System of National Accounts, 2016-17. Cat. No 5204.0. Australian Bureau of Statistics, Canberra, Australia. http://www.abs.gov.au/AUSSTATS/abs@.nsf/DetailsPage/5204.02016-17?OpenDocument (Accessed 16 December 2017).

ABS, 2017b. Labour Force, Australia, Detailed, Quarterly, Nov 2017. Cat. No 6291.0.55.003. Australian Bureau of Statistics, Canberra, Australia. Available at: http://www.abs.gov.au/ausstats/abs@.nsf/mf/6291.0.55.003 (Accessed 16 December 2017).

Allen, P., Chatterton, T., 2013. Carbon reduction scenarios for 2050: An explorative analysis of public preferences. Energy Policy 63, 796-808. https://doi.org/10.1016/j.enpol.2013.08.079

Anand, S., Vrat, P., Dahiya, R.P., 2006. Application of a system dynamics approach for assessment and mitigation of CO2 emissions from the cement industry. Journal of Environmental Management 79, 383-398. https://doi.org/10.1016/j.jenvman.2005.08.007

APS, 2010. Integrating Renewable Electricity on the Grid. American Physical Society, Washington, D.C. USA.

Ayres, R.U., Warr, B., 2009. The Economic Growth Engine: How Energy and Work Drive Material Prosperity. Edward Elgar, Cheltenham, UK.

Banister, D., Hickman, R., 2013. Transport futures: Thinking the unthinkable. Transport Policy 29, $283-293$. https://doi.org/10.1016/j.tranpol.2012.07.005

Bank of England, 2015. Evaluating forecast performance. London, UK.

Barker, T., 1981. Projecting economic structure with a large-scale econometric model. Futures 13, $458-467$.

Barker, T.S., 1978. Towards Strategic Paths in Economic Planning, in: Stone, J.R.N., Peterson, A.W.A. (Eds.), Econometric Contributions to Public Policy, International Economic Association. Presented at the International Economic Association, Urbino, Italy, Palgrave Macmillan, London, UK, pp. 84-110.

Barker, T., Borooah, V., van der Ploeg, R., Winters, A., 1980. The Cambridge multisectoral dynamic model: An instrument for national economic policy analysis. Journal of Policy Modeling 2, 319-344. doi:10.1016/0161-8938(80)90027-7

Barker, T., Ekins, P., Foxon, T., 2007. The macro-economic rebound effect and the UK economy. Energy Policy 35, 49354946. doi:10.1016/j.enpol.2007.04.009

Barker, T., Peterson, W. (Eds.), 1987. The Cambridge Multisectoral Dynamic Model, Cambridge Studies in Applied Econometrics. Cambridge University Press, Cambridge, UK.

BEA, 2017a. Gross-Domestic-Product-(GDP)-by-Industry Data: Value Added. U.S. Bureau of Economic Analysis, Washington, DC, USA. https://www.bea.gov/industry/gdpbyind_data.htm (accessed 16 December 2017).

BEA, 2017b. Imputed rental of owner-occupied housing [A2013C1A027NBEA]. U.S. Bureau of Economic Analysis, Washington, DC, USA. https://fred.stlouisfed.org/series/A2013C1A027NBEA (accessed 16 December 2017).

BEA, 2017c. Gross Domestic Product: Implicit Price Deflator [GDPDEF]. U.S. Bureau of Economic Analysis, Washington, DC, USA. https://fred.stlouisfed.org/series/GDPDEF (accessed 16 December 2017).

BEIS, 2016. Digest of United Kingdom energy statistics 2016. Department for Business, Energy and Industrial Strategy, London, UK.

BEIS, 2017. 2015 UK Greenhouse Gas Emissions, Final Figures. Department for Business, Energy and Industrial Strategy, London, UK.

Bernardo, G., D’Alessandro, S., 2016. Systems-dynamic analysis of employment and inequality impacts of low-carbon investments. Environmental Innovation and Societal Transitions 21, 123-144. https://doi.org/10.1016/j.eist.2016.04.006

Beugin, D., Jaccard, M., 2012. Statistical Simulation to Estimate Uncertain Behavioral Parameters of Hybrid EnergyEconomy Models. Environ Model Assess 17, 77-90. https://doi.org/10.1007/s10666-011-9276-0

Bithas, K., Kalimeris, P., 2013. Re-estimating the decoupling effect: Is there an actual transition towards a less energyintensive economy? Energy 51, 78-84. doi:10.1016/j.energy.2012.11.033

BIS, 2010. Manufacturing in the UK: An economic analysis of the sector (BIS Economics Paper No. 10A). Department for Business, Innovation and Skills, London, UK.

Bishop, P., Hines, A., Collins, T., 2007. The current state of scenario development: an overview of techniques. Foresight 9, 5-25. doi:10.1108/14636680710727516

BLS, 2017. Table 17. Employed persons by industry, sex, race, and occupation. U.S. Bureau of Labor Statistics, Washington, DC, USA. https://www.bls.gov/cps/tables.htm (accessed 16 December 2017).

Burt, G., 2011. Towards the integration of system modelling with scenario planning to support strategy: the case of the UK energy industry. Journal of the Operational Research Society 62, 830-839. https://doi.org/10.1057/jors.2010.47

Cambridge Econometrics, 2014. E3ME Technical Manual, Version 6.0. Cambridge, UK.

Cambridge Econometrics, 2015. Quantifying Uncertainty in Baseline Emissions Projections. Cambridge, UK. 
SH. Roberts, CJ. Axon, NH. Goddard, BD. Foran, \& BS. Warr (2019). Modelling socio-economic and energy data to generate business-as-usual scenarios for carbon emissions. J. Cleaner Production, 207, pp.980-997. https://doi.org/10.1016/j.jclepro.2018.10.029

Castaneda, M., Franco, C.J., Dyner, I., 2017. Evaluating the effect of technology transformation on the electricity utility industry. Renewable and Sustainable Energy Reviews 80, 341-351. https://doi.org/10.1016/j.rser.2017.05.179

CCC, 2015. The Fifth Carbon Budget: The next step towards a low-carbon economy. Committee on Climate Change, London, UK.

CCC, 2017. Meeting Carbon Budgets - 2017 Progress Report to Parliament. Committee on Climate Change, London, UK.

Chaudry, M., Abeysekera, M., Hosseini, S.H.R., Jenkins, N., Wu, J., 2015. Uncertainties in decarbonising heat in the UK. Energy Policy 87, 623-640. doi:10.1016/j.enpol.2015.07.019

Chermack, T.J., Coons, L.M., 2015. Scenario planning: Pierre Wack’s hidden messages. Futures 73, $187-193$. doi:10.1016/j.futures.2015.08.012

Concensus Economics, 2015. A Digest of International Economic Forecasts. London, UK.

Csereklyei, Z., Stern, D.I., 2015. Global energy use: Decoupling or convergence? Energy Economics 51, $633-641$. doi:10.1016/j.eneco.2015.08.029

Dagoumas, A., 2014. Modelling socio-economic and energy aspects of urban systems. Sustainable Cities and Society 13, 192-206. doi:10.1016/j.scs.2013.11.003

Daly, H.E., Fais, B., 2014. UK TIMES Model Overview. UCL Energy Institute, London, UK.

DANE, 2017a. Cuentas económicas nacionales trimestrales - PIB [Quarterly national economic accounts - GDP]. Departamento Administrativo Nacional de Estadstica, Bogota, Colombia.

DANE, 2017b. Colombia Matrices de oferta a precios Corrientes [National Accounts - Accounts of Goods and Services]. Departamento Administrativo Nacional de Estadstica, Bogota, Colombia.

DANE, 2017c. Colombia imputados y alquileres imputados [charged and imputed rentals]. Departamento Administrativo Nacional de Estadstica, Bogota, Colombia.

http://www.dane.gov.co/files/investigaciones/pib/anuales/cpgcf_base2000/C34.xls (accessed 16 December 2017).

DANE, 2017d. Gran Encuesta Integrada de Hogares 2001-2016 [Integrated Household Survey]. Departamento Administrativo Nacional de Estadstica, Bogota, Colombia.

http://www.dane.gov.co/files/investigaciones/boletines/ech/ech/anexo_empleo_ene_17.xls (accessed 16 December 2017).

DECC, 2010. 2050 Pathway Analysis. Department of Energy and Climate Change, London, UK. https://www.gov.uk/guidance/2050-pathways-analysis (accessed 16 December 2017).

DECC, Climate-KIC, IEA, 2015. Costs in Global Calculator: methodology paper. Department of Energy and Climate Change, London, UK.

Demski, C., Spence, A., Pidgeon, N., 2017. Effects of exemplar scenarios on public preferences for energy futures using the my2050 scenario-building tool. Nature Energy 2, 17027. https://doi.org/10.1038/nenergy.2017.27

DGBAS, 2017a. National Accounts Yearbook. Directorate General of Budget, Accounting and Statistics, Executive Yuan Taipei, Taiwan. http://eng.stat.gov.tw/ct.asp?xItem=37408\&CtNode=5347\&mp=5 (accessed 16 December 2017).

DGBAS, 2017b. Labor Force Time Series. Directorate General of Budget, Accounting and Statistics, Executive Yuan Taipei, Taiwan. http://eng.stat.gov.tw/ct.asp?xItem=15761\&ctNode=1609\&mp=5 (accessed 16 December 2017).

Dias, M.A. de P., Vianna, J.N. de S., Felby, C., 2016. Sustainability in the prospective scenarios methods: A case study of scenarios for biodiesel industry in Brazil, for 2030. Futures 82, 1-14. doi:10.1016/j.futures.2016.06.005

Dreborg, K.H., 1996. Essence of backcasting. Futures 28, 813-828. https://doi.org/10.1016/S0016-3287(96)00044-4

Ekins, P., Anandarajah, G., Strachan, N., 2011. Towards a low-carbon economy: scenarios and policies for the UK. Climate Policy 11, 865-882. https://doi.org/10.3763/cpol.2010.0126

Eyre, N., Baruah, P., 2015. Uncertainties in future energy demand in UK residential heating. Energy Policy 87, $641-653$. doi:10.1016/j.enpol.2014.12.030

Fazeli, R., Davidsdottir, B., 2017. Energy performance of dwelling stock in Iceland: System dynamics approach. Journal of Cleaner Production 167, 1345-1353. https://doi.org/10.1016/j.jclepro.2017.05.009

Federal Open Market Committee, 2012. . Board of Govenors of the Federal Reserve System. URL http://www.frbsf.org/education/publications/doctor-econ/2013/may/numerical-thresholds-federal-funds-rateunemployment-inflation (accessed 11.1.16).

Guenther-Lübbers, W., Bergmann, H., Theuvsen, L., 2016. Potential analysis of the biogas production - as measured by effects of added value and employment. Journal of Cleaner Production 129, 556-564. https://doi.org/10.1016/j.jclepro.2016.03.157

Heijden, K.van der, 2004. Scenarios: The Art of Strategic Conversation, 2nd ed. John Wiley \& Sons, Chichester, UK.

Hickman, R., Ashiru, O., Banister, D., 2010. Transport and climate change: Simulating the options for carbon reduction in London. Transport Policy 17, 110-125. https://doi.org/10.1016/j.tranpol.2009.12.002

Hills, S., Thomas, R., Dimsdale, N., 2010. The UK recession in context-what do three centuries of data tell us? Bank of England Quarterly Bulletin Q4, 277-291.

Hobson, K., Lynch, N., 2016. Diversifying and de-growing the circular economy: Radical social transformation in a resource-scarce world. Futures 82, 15-25. doi:10.1016/j.futures.2016.05.012 
SH. Roberts, CJ. Axon, NH. Goddard, BD. Foran, \& BS. Warr (2019). Modelling socio-economic and energy data to generate business-as-usual scenarios for carbon emissions. J. Cleaner Production, 207, pp.980-997. https://doi.org/10.1016/j.jclepro.2018.10.029

Holland, R., Ketsopoulou, I., Beaumont, N., Austen, M., Hooper, T., Gross, R., Heptonstall, P., Watson, J., Taylor, G., 2016. How consistent and comparable are ecosystem services and energy system scenarios? (Working Paper). UKERC, London, UK.

Höjer, M., Ahlroth, S., Dreborg, K.-H., Ekvall, T., Finnveden, G., Hjelm, O., Hochschorner, E., Nilsson, M., Palm, V., 2008. Scenarios in selected tools for environmental systems analysis. Journal of Cleaner Production 16, 1958-1970. doi:10.1016/j.jclepro.2008.01.008

HM Government, 2008. Climate Change Act. HMSO, London, UK.

Hughes, N., Strachan, N., 2010. Methodological review of UK and international low carbon scenarios. Energy Policy 38, 6056-6065. https://doi.org/10.1016/j.enpol.2010.05.061

IPCC, 2015. Climate change 2014: synthesis report. Intergovernmental Panel on Climate Change, Geneva, Switzerland.

Jaccard, M., Agbenmabiese, L., Azar, C., De, O., Fischer, C., Fisher, B., Hughes, A., Ohadi, M., Kenji, Y., Zhang, X., 2012. Chapter 22 - Policies for Energy System Transformations: Objectives and Instruments, in: Global Energy Assessment - Toward A Sustainable Future. Cambridge University Press, Cambridge, UK, pp. 1549-1602.

Jebaraj, S., Iniyan, S., 2006. A review of energy models. Renewable and Sustainable Energy Reviews 10, $281-311$. doi:10.1016/j.rser.2004.09.004

Kang, M., Lee, J.-D., 2007. Evolutionary Characteristics of China’s Intermediate Manufactures. China \& World Economy 15, 1-21. doi:10.1111/j.1749-124X.2007.00089.x

Keen, S., 1995. Finance and economic breakdown: Modeling Minsky’s “financial instability hypothesis.” Journal of Post Keynesian Economics 17, 607-635.

Keen, S., 2013. A monetary Minsky model of the Great Moderation and the Great Recession. Journal of Economic Behavior \& Organization 86, 221-235. doi:10.1016/j.jebo.2011.01.010

Kishita, Y., McLellan, B.C., Giurco, D., Aoki, K., Yoshizawa, G., Handoh, I.C., 2017. Designing backcasting scenarios for resilient energy futures. Technological Forecasting and Social Change 124, 114-125. https://doi.org/10.1016/j.techfore.2017.02.001

Krewitt, W., Simon, S., Graus, W., Teske, S., Zervos, A., Schäfer, O., 2007. The $2^{\circ} \mathrm{C}$ scenario-A sustainable world energy perspective. Energy Policy 35, 4969-4980. https://doi.org/10.1016/j.enpol.2007.04.034

Lenzen, M., Malik, A., Foran, B., 2016. Decoupling global environmental pressure and economic growth: scenarios for energy use, materials use and carbon emissions. Journal of Cleaner Production 132, 45-56. doi:10.1016/j.jclepro.2015.06.10

Lequiller, F., Blades, D., 2014. Understanding National Accounts. $2^{\text {nd }}$ edition, OECD: Paris.

Liao, H., Cai, J.-W., Yang, D.-W., Wei, Y.-M., 2016. Why did the historical energy forecasting succeed or fail? A case study on IEA's projection. Technological Forecasting and Social Change 107, 90-96. doi:10.1016/j.techfore.2016.03.026

Loulou, R., Labriet, M., 2008. ETSAP-TIAM: the TIMES integrated assessment model Part I: Model structure. CMS 5, 740. https://doi.org/10.1007/s10287-007-0046-z

Loulou, R., Remne, U., Kanudia, A., Lehtila, A., Goldstein, G., 2005. Documentation for the TIMES Model. International Energy Agency, Paris, France.

McDowall, W., Solano Rodriguez, B., Usubiaga, A., Acosta Fernández, J., 2018. Is the optimal decarbonization pathway influenced by indirect emissions? Incorporating indirect life-cycle carbon dioxide emissions into a European TIMES model. Journal of Cleaner Production 170, 260-268. https://doi.org/10.1016/j.jclepro.2017.09.132

McGlade, C., Pye, S., Watson, J., Bradshaw, M., Ekins, P., 2016. The future role of natural gas in the UK (No. UKERC/RR/RV/2016/01). UKERC, London, UK.

Mai, T., Logan, J., Blair, N., Sullivan, P., Bazilian, M., 2013. Re-Assume A Decision Maker’s Guide to Evaluating Energy Scenarios, Modeling, and Assumptions. National Renewable Energy Laboratory, Golden CO, USA.

Nagy, K., Körmendi, K., 2012. Use of renewable energy sources in light of the "New Energy Strategy for Europe 20112020.” Applied Energy, Smart Grids 96, 393-399. https://doi.org/10.1016/j.apenergy.2012.02.066

Notton, L. (Ed.), 2016. Federal Regulatory Directory, 17th ed. CQ Press, Thousand Oaks, CA, USA.

OBR, 2016. Economic and fiscal outlook. Office for Budget Responsibility, London, UK.

OECD, 2007. Moving Up the Value Chain: Staying Competitive in the Global Economy. Organisation for Economic Cooperation and Development, Paris, France.

OECD, 2014. Long-term baseline projections (No. 95). Organisation for Economic Co-operation and Development, Paris, France. DOI: 10.1787/eo-data-en

Olivier, J.G.J., Janssens-Maenhout, G., Muntean, M., Peters, J.A.H.W., 2016. Trends in global CO2 emissions (No. PBL: 2375 / JRC: 103428). Netherlands Environmental Assessment Agency and European Commission, Joint Research Centre, The Hague, Netherlands.

ONS, 2010. Capital Stocks reconciliation with formation and depreciation. Email from B. Omundsen to S.H. Roberts, 20th April.

ONS, 2014a. Capital stocks, consumption of fixed capital: 2013. Office for National Statistics, Newport, UK. 
SH. Roberts, CJ. Axon, NH. Goddard, BD. Foran, \& BS. Warr (2019). Modelling socio-economic and energy data to generate business-as-usual scenarios for carbon emissions. J. Cleaner Production, 207, pp.980-997. https://doi.org/10.1016/j.jclepro.2018.10.029

ONS, 2014b. Impact of the methodological changes to the estimation of capital stocks and consumption of fixed capital. Office for National Statistics, Newport, UK.

ONS, 2015a. United Kingdom National Accounts, The Blue Book: 2015 Edition. Office for National Statistics, Newport, UK.

ONS, 2015b. UK Labour Market: October 2015. Office for National Statistics, Newport, UK.

ONS, 2016. JOBS02: Workforce jobs by industry. Office for National Statistics, Newport, UK.

Oxford Economics, 2011. Fossil fuel price shocks and a low carbon economy. Oxford Economics, Oxford, UK.

Pfenninger, S., Hawkes, A., Keirstead, J., 2014. Energy systems modeling for twenty-first century energy challenges. Renewable and Sustainable Energy Reviews 33, 74-86. doi:10.1016/j.rser.2014.02.003

Radzicki, M.J., 1988. Institutional Dynamics: An Extension of the Institutionalist Approach to Socioeconomic Analysis. Journal of Economic Issues 22, 633-665.

Roberts, S.H., Axon, C.J., Foran, B.D., Goddard, N.H., Warr, B.S., 2015. A framework for characterising an economy by its energy and socio-economic activities. Sust. Cities Soc. 14, 99-113. doi:10.1016/j.scs.2014.08.004

Roberts, S.H., Axon, C.J., Goddard, N.H., Foran, B.D., Warr, B.S., 2016. A robust data-driven macro-socioeconomicenergy model. Sustainable Production and Consumption 7, 16-36. doi:10.1016/j.spc.2016.01.003

Robertson, S., 2016. A longitudinal quantitative-qualitative systems approach to the study of transitions toward a low carbon society. Journal of Cleaner Production, 128, 221-233. https://doi.org/10.1016/j.jclepro.2015.04.074

Robinson, J.B., 1982. Energy backcasting A proposed method of policy analysis. Energy Policy 10, 337-344. https://doi.org/10.1016/0301-4215(82)90048-9

Saavedra M., M.R., de O. Fontes, C.H., M. Freires, F.G., 2018. Sustainable and renewable energy supply chain: A system dynamics overview. Renewable and Sustainable Energy Reviews 82, 247-259. https://doi.org/10.1016/j.rser.2017.09.033

Sadorsky, P., 2011. Some future scenarios for renewable energy. Futures, Special Issue: Energy Futures 43, $1091-1104$. doi:10.1016/j.futures.2011.07.008

Shanmugalingam, S., Puttick, R., Westlake, S., 2010. Rebalancing act (No. RA/54). National Endowment for Science, Technology and the Arts, London, UK.

Skea, J., Ekins, P., Winskel, M. (Eds.), 2011. Energy 2050: Making the Transition to a Secure Low-Carbon Energy System. Earthscan, London, UK.

Spataru, C., Drummond, P., Zafeiratou, E., Barrett, M., 2015. Long-term scenarios for reaching climate targets and energy security in UK. Sustainable Cities and Society 17, 95-109. https://doi.org/10.1016/j.scs.2015.03.010

Sterman, J., 2000. Business Dynamics: Systems Thinking and Modeling for a Complex World. McGraw-Hill, Boston, USA.

Strachan, N., 2011. Business-as-Unusual: Existing policies in energy model baselines. Energy Economics 33, $153-160$. doi:10.1016/j.eneco.2010.10.009

Strachan, N., Kannan, R., 2008. Hybrid modelling of long-term carbon reduction scenarios for the UK. Energy Economics 30, 2947-2963. https://doi.org/10.1016/j.eneco.2008.04.009

Taylor, P.G., Upham, P., McDowall, W., Christopherson, D., 2014. Energy model, boundary object and societal lens: 35 years of the MARKAL model in the UK. Energy Research \& Social Science 4, 32-41. doi:10.1016/j.erss.2014.08.007

Trutnevyte, E., McDowall, W., Tomei, J., Keppo, I., 2016. Energy scenario choices: Insights from a retrospective review of UK energy futures. Renewable and Sustainable Energy Reviews 55, 326-337. https://doi.org/10.1016/j.rser.2015.10.067

UNFCCC, 2016. Report of the Conference of the Parties on its twenty-first session (No. FCCC/CP/2015/10/Add.1). United Nations Framework Convention on Climate Change, Bonn, Germany.

United Nations, European Commission, International Monetary Fund, Organisation for Economic Co-operation and Development, World Bank (Eds.), 2009. System of National Accounts 2008. United Nations, New York, USA.

Wen, Z., Di, J., Yu, X., Zhang, X., 2017. Analyses of CO2 mitigation roadmap in China's power industry: Using a Backcasting Model. Applied Energy 205, 644-653. https://doi.org/10.1016/j.apenergy.2017.08.026

Xue, Y., Guan, H., Corey, J., Zhang, B., Yan, H., Han, Y., Qin, H., 2017. Transport Emissions and Energy Consumption Impacts of Private Capital Investment in Public Transport. Sustainability 9, 1760. https://doi.org/10.3390/su9101760

Yang, L., 2016. China’s Growth Miracle: Past, Present, and Future. United Nations Research Institute for Social Development, Geneva, Switzerland.

\section{Acknowledgements}

We are grateful for the care taken in converting data from the 7see framework into accurate, readable drawing of the block diagrams and graphs by Elisa Magnini and Thalis Laspias in the Arup University's Foresight+Research+Innovation group. We would like to thank the anonymous reviewers for their helpful comments. This research was supported financially by Arup’s internal Design and Technical Fund. 
SH. Roberts, CJ. Axon, NH. Goddard, BD. Foran, \& BS. Warr (2019). Modelling socio-economic and energy data to generate business-as-usual scenarios for carbon emissions. J. Cleaner Production, 207, pp.980-997. https://doi.org/10.1016/j.jclepro.2018.10.029

\section{Appendix A: Coefficients and the investment loop for each industry}

Here we detail all the time-dependent coefficients we apply to the economic volume flows of each industry. We summarise these by introducing the 'investment loop' of an industry's FC as a source of production which supplies final demand, then via GFCF back to FC.

\section{A.1 The investment loop}

As an example, we show the investment loop for manu (manufacturing) in Fig. A.1. We explain this schematic by starting at $\mathrm{FC}_{4}$ (the fixed capital of manu) initially following the connected arrows going anti-clockwise around the loop. The goods output of $F C_{4}$ starts as $p_{4}$ and proceeds through forms $q_{4}, r_{4}$ and $s_{4}$ to $f_{4}$. The main steps in this progression are:

1. Addition of imports, represented by a demand arrow.

2. Diversion of output as supply of IC to other industries, represented by demand arrows by those industries.

3. Addition of input as IC from other industries, represented by demand arrows by manu.

4. Addition of input as TTM from serv LT, represented by a demand arrow by manu.

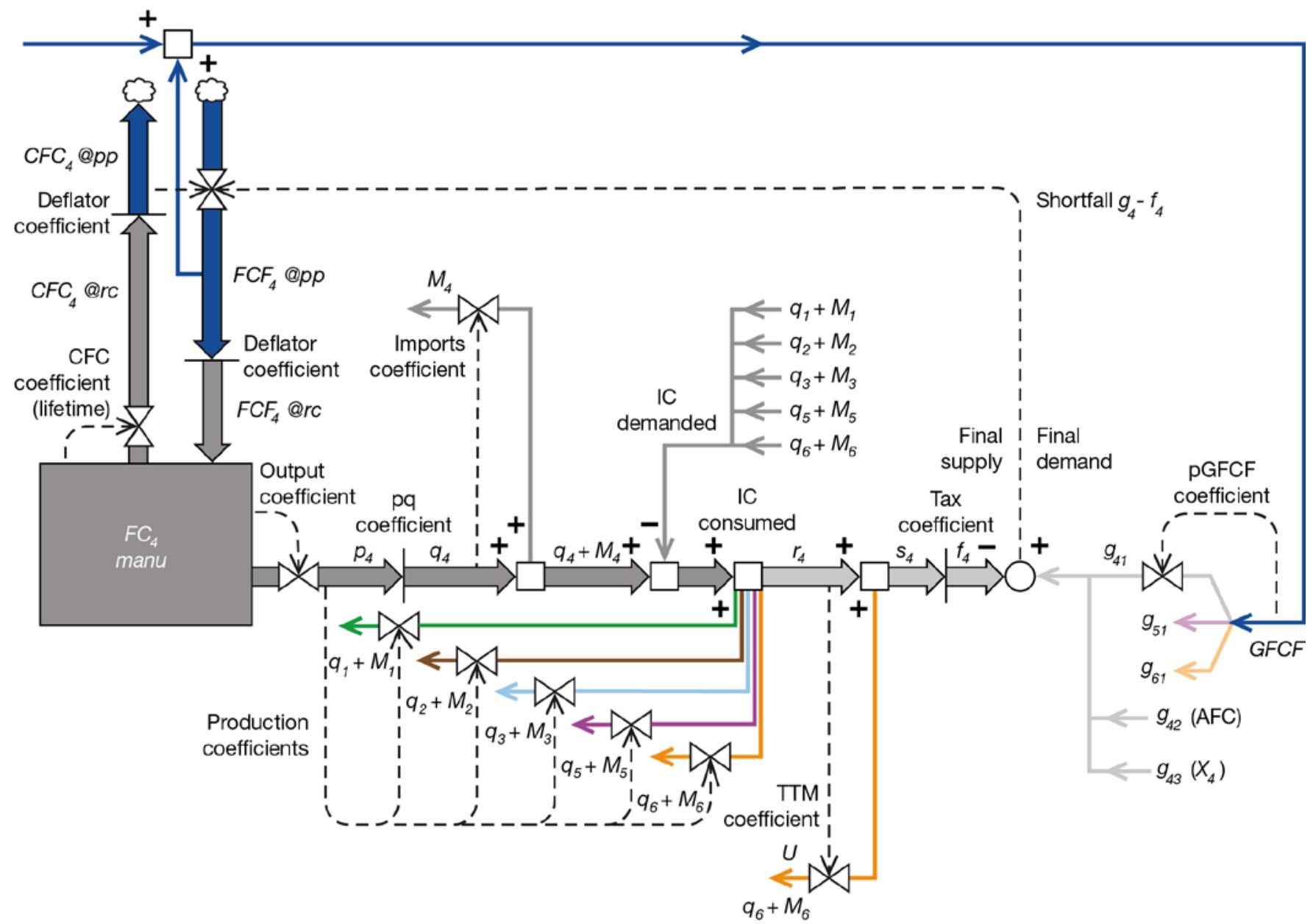

Figure A.1. Investment loop for manu (manufacturing, $j=4$ ) showing all the coefficients and IC. The demand for FCF in response to shortfall feedback and need to replace CFC are at purchasers’ prices (@pp). The industry-specific deflator coefficient converts FCF to 'at resale cost' (@rc) when it increments FC according to Eqn. (A.1).

At $f_{4}$ the output of manu is in its final form to meet final demand. Since the arrows change to demand (beginning with $g_{4}$ ), we continue anti-clockwise around the loop but now against the arrow directions. Of the three types of final demand, we follow along the manu component of investment, GFCF, merging with contributions from $g_{5}$ of $c n s t r$ and $g_{6}$ of $\operatorname{serv} L R$. The GFCF section of the loop fulfils the FCF demand of all FC 
SH. Roberts, CJ. Axon, NH. Goddard, BD. Foran, \& BS. Warr (2019). Modelling socio-economic and energy data to generate business-as-usual scenarios for carbon emissions. J. Cleaner Production, 207, pp.980-997. https://doi.org/10.1016/j.jclepro.2018.10.029

including that of manu, $\mathrm{FCF}_{4}$, shown here. Finally we continue anti-clockwise with the direction of arrows to arrive back at our starting point, $F_{4}$.

The investment loop is crossed by a dashed arrow of shortfall from a shortfall circle. The manu loop applies control (Roberts et al., 2016) where the shortfall circle denotes the point in the loop where a mismatch of supply to demand is derived at each time-step. This mismatch gives rise to a change in $F C_{4}$ to resolve the mismatch.

FC represents the value of all fixed assets used in production consisting of buildings, plant and machinery, and transport (ONS, 2014b). Data on FC is generally calculated by the perpetual inventory method (PIM) and provided as gross and net (ONS, 2014b). Gross capital stocks is how much it would cost to buy as new (or replace) the economy's assets. Net capital stocks is the market (resale) value of fixed assets reflecting depreciation. We use the net form since changes each year depend solely on FCF and CFC (ONS, 2010), as

$$
F C(t)=F C(t-1)+F C F(t)-C F C(t)
$$

We include the flows for CFC in our schematic of the investment loop because they show how FC decreases and contribute to demand for FCF.

\section{A.2 Coefficients}

From $p_{4}$ to $q_{4}$ we change from output 'as categorised by industry' to 'as categorised by product' (Roberts et al., 2016). We apply this step change in flow using the pq coefficient, which is specific to each industry. We note that the sum of $q$ resulting from the set of pq coefficients over all industries is constrained to equal the sum of $p$ before the application of pq coefficients. We calculate any discrepancy of the sum of $q$ to the sum of $p$ and subtract this from $q$ for the largest output (serv $L R$ in the UK case). Correcting this discrepancy is necessary for the future projection as a consequence of each pq coefficient being trended forward separately. Every coefficient has a denominator and we note how we choose this for $p$ through to $f$.

- For the production coefficient we use $p$ for the denominator, rather than $q$, since the inputs necessary for the production process would be directly related to output from FC.

- For the imports coefficient, imports are categorised by products so we use $q$ for the denominator.

- For the TTM coefficient we use $r$ for the denominator since this is the size of flow at this point to which the margins of TTM are applied.

In the flow of output from $p$ to GFCF, there is a change from 'at basic prices' (@bp) to 'at purchasers' prices' (@pp) after the addition of taxes (less subsidies) on products. Since we do not keep an account of revenues, such as from taxation, we apply a step change at $s_{4}$ to $f_{4}$ by use of the tax coefficient.

The pGFCF coefficient is taken as proportions of the three larger outputs, manu, cnstr and serv LR, that make up GFCF, these proportions summing to unity. We trend only for the two smaller proportions of manu and serv $L R$, and derive the larger proportion of cnstr by the difference from unity.

Historical data is provided at current prices and chain volume measures (CVM). We need to apply deflator coefficients so that the deflated values are the most appropriate proxies for the quantities they represent. For $p$ through to GFCF, including imports, the relationship between current prices and CVM is generally taken as the GDP deflator. We apply this single GDP deflator across $p$ through to GFCF for all industries since they all contribute to the same headline indicator of GDP itself. For the FC of each industry, we do not need to apply an industry-wide deflator since industry FC values are never combined numerically. Furthermore we prefer to use industry-specific FC deflators so that each FC is a good proxy for its industry and the best basis for output $p$ following around our investment loop via its output coefficient. We derive the deflator coefficient for each industry for FCF at resale cost (@rc) from data @pp and at CVM. Since CFC affects the demand for FCF, we convert it to @pp before this connection.

To compute CFC from FC, we could use the CFC coefficient as calibrated from historical data. However we prefer to work with its inverse, the lifetime (LT) of FC, because the national accounts assign lifetimes to the components of FC in applying the PIM. We do not distinguish between these components but derive by the process below a single $L T$ value that applies over the full historical period. After initialising $F C_{\bmod }(0)$ to the historical value, $F C_{\text {hist }}(0)$, we compute the model time-series, $F C_{\text {mod }}(t)$, over the full historical period for a selection of values of $L T$, thus 
SH. Roberts, CJ. Axon, NH. Goddard, BD. Foran, \& BS. Warr (2019). Modelling socio-economic and energy data to generate business-as-usual scenarios for carbon emissions. J. Cleaner Production, 207, pp.980-997. https://doi.org/10.1016/j.jclepro.2018.10.029

$F C_{\text {mod }}(t+1)=\frac{F C_{\text {mod }}(t)+F C F_{\text {hist }}(t)-F C_{\text {mod }}(t)}{L T}$

We select $L T$ for the best match of $F C_{\text {mod }}(t)$ to $F C_{\text {hist }}(t)$ over the historical period. In some situations we might need to change to a variable lifetime, $L T(t)$, to achieve a good match.

\section{Appendix B: Coefficients for dwellings, utilities, and transport}

For industries we use FC to quantify their infrastructure (Appendix A) so that we can apply stocks and flows analysis in our system dynamics model to endogenise FCF, and thus GFCF of final demand. Metrics for nonindustry need to be treated differently so that as denominators they are a better basis for resulting flows, such as use of energy.

\section{B.1 Dwellings}

We show dwellings in Fig. B.1. The SNA (United Nations et al., 2009) notes that GFCF includes "major improvements, additions or extensions to fixed assets, both machinery and structures, which improve their performance, increase their capacity or prolong their expected working lives”. Therefore we distinguish between FCF to new build and improvement and find that for the physical assets the dwelling number ( $D N)$ is a better representation. The stock of dwellings, DN gives rise to (real or imputed) rental, from which we derive the rental coefficient similar to the output coefficient in Fig. A.1. Incorporating rental enables a 7see model to compute GDP. However, rental can be sensitive to a surplus or shortfall of dwellings in relation to the number of households thus we derive inputs using utility coefficients with $D N$ as the denominator.

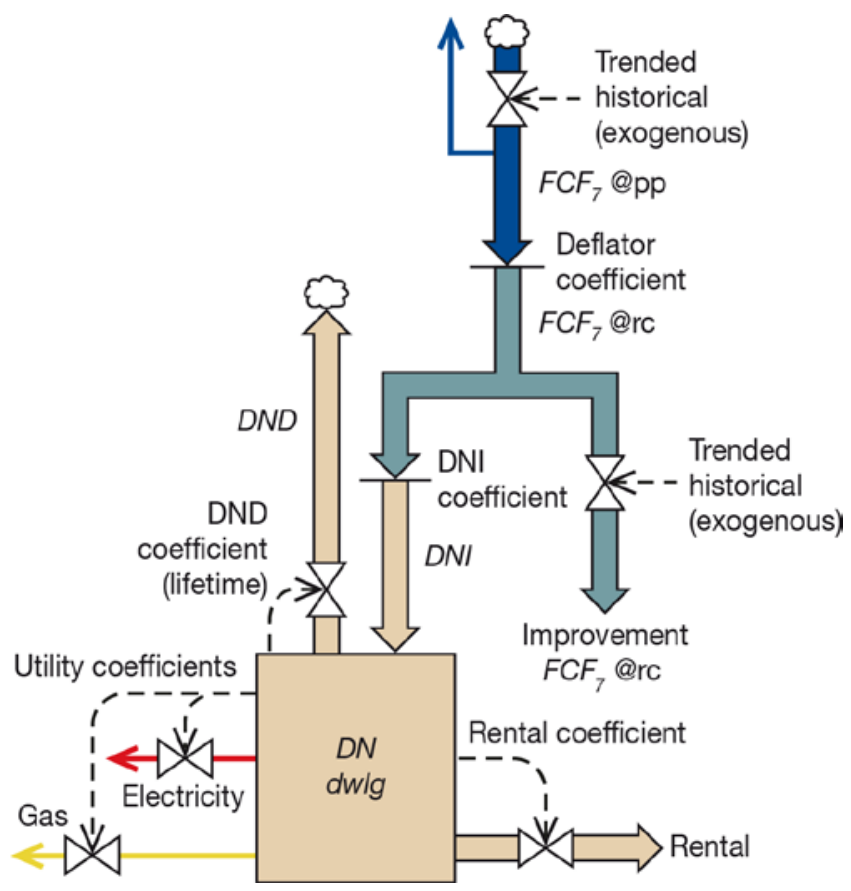

Figure B.1. Schematic for dwellings. Data, concepts, coefficients and control. 
SH. Roberts, CJ. Axon, NH. Goddard, BD. Foran, \& BS. Warr (2019). Modelling socio-economic and energy data to generate business-as-usual scenarios for carbon emissions. J. Cleaner Production, 207, pp.980-997. https://doi.org/10.1016/j.jclepro.2018.10.029

\section{B.2 Utilities}

A better proxy than FC is the power specification of electricity generating capacity (GC) as MW (megawatts). Fig. B.2 shows examples offshore wind turbine and CCGT GC.

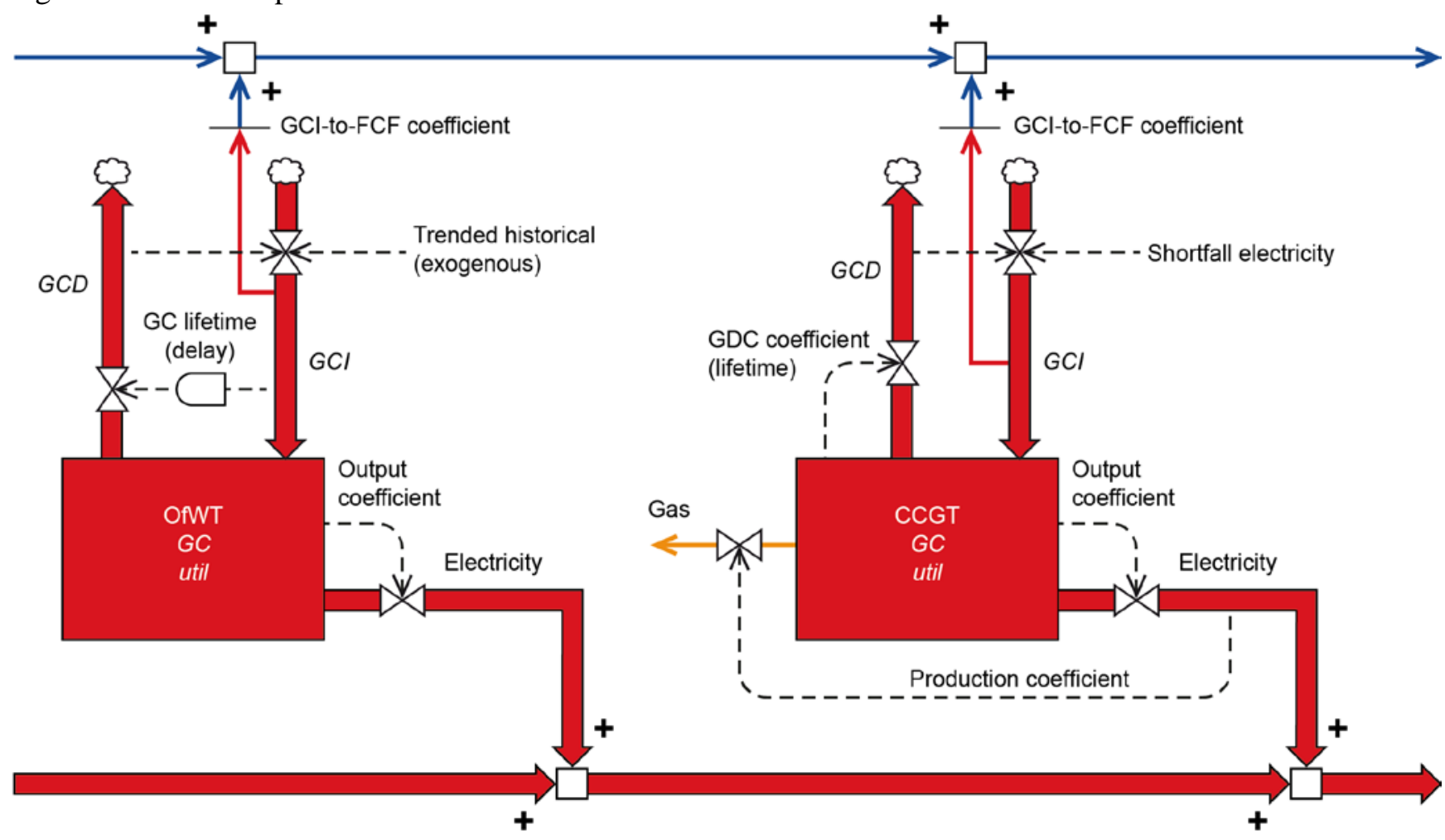

Figure B.2. Schematic for power generation components added to total FCF demand for utility industry (along top) and total supply of electricity (along bottom).

CCGT is a mature technology so we set the level of the generating capacity decrease (GCD) according to the lifetime of the GC. CCGT needs a fuel whose level is determined by the production coefficient. We consider it reasonable for the projected period to use CCGT to match electricity demand, thus its generating capacity increase (GCI) is set by shortfall electricity. For the resulting demand for GCI, this is converted to a demand for FCF of the whole economy by the GCI-to-FCF coefficient shown. This is the margin cost of building the next unit of MW capacity. The schematic for coal fired generation would be very similar to CCGT GC, only differing by GCI being set exogenously.

The schematic shown for offshore wind turbine (OfWT) GC differs from CCGT GC in two ways. First, as an example of renewable generation it has no demand for an input fuel, and secondly it is a young technology with installation growing rapidly from a low stock, thus most of the stock of GC is new. It would be inappropriate to apply a stock-wide average lifetime to derive CFC, as for the mature technology of CCGT GC. Instead we presume that replacement is needed the lifetime after building, which we implement for CFC by a delay from FCF of duration GC lifetime.

\section{B.3 Transport}

We divide transport into passenger and freight, then between different modes (Roberts et al, 2015). We apply the method of relationship coefficients to the larger vehicle groups: cars, LCV (light commercial vehicles) and HGV (heavy goods vehicles). We show in Fig. B.3 the application of coefficients for HGV based on their number, HN. 
SH. Roberts, CJ. Axon, NH. Goddard, BD. Foran, \& BS. Warr (2019). Modelling socio-economic and energy data to generate business-as-usual scenarios for carbon emissions. J. Cleaner Production, 207, pp.980-997. https://doi.org/10.1016/j.jclepro.2018.10.029

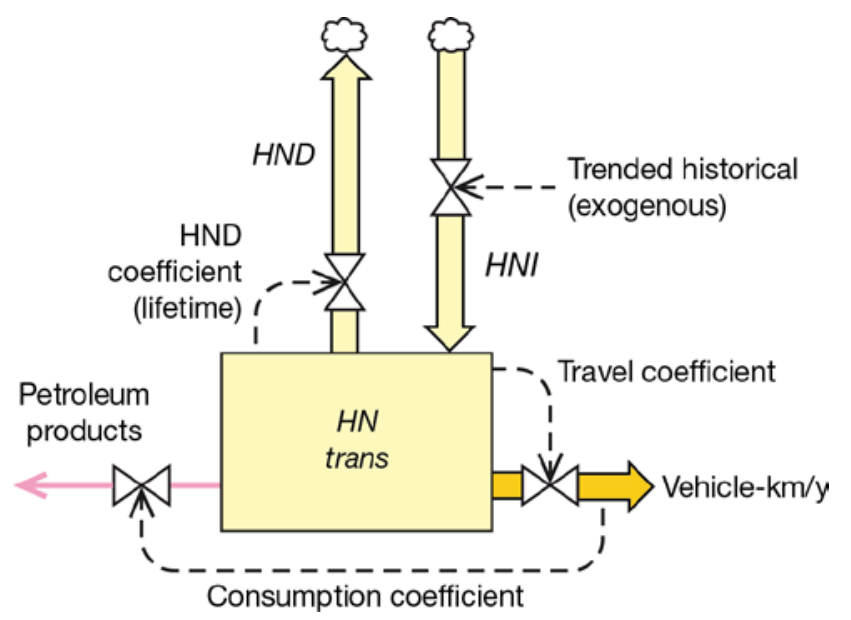

Figure B.3. Schematic for road transport for the case of HGV, heavy goods vehicles.

\section{Appendix C: Apportioning industry inputs and impacts \\ C.1 Apportioning industry inputs or impacts to components of final demand}

Inputs to production such as jobs and fossil fuels can be apportioned to final outputs of the economy. For our case study the key input is fossil fuels and we would like to know how $\mathrm{CO}_{2}$ emissions can be attributed to components of final demand. An apportioned input or impact divided by the economic volume expenditure is the intensity of use per unit of output. We apportion inputs and impacts in proportion to the IC of industries. For simplicity, we take all the industry interaction as between the products of the three larger industries of manu, cnstr and $\operatorname{serv} L R(j=4$ to 6$)$.

Let $b_{j k \text { - }}$ be the proportion of output at basic prices plus imports $M$ of products $j$ that are supplied for IC to industry $k$ for the final supply of products $k$. We note that production categorised by industry, $p$, differs from production categorised by products, $q$, (Fig. A.1) but we simplify by associating all inputs or impacts of industry $j$ to products $q_{j}$

$b_{j k-}=\frac{\text { IC_of_products_j_by_industry_k }}{q_{j}+M_{j}}$,

for each $j=4-6$,

$\sum_{k=4}^{6} b_{j k-}=1$.

In the special case of services to manu, we take $b_{64}$ also to include provision of services as transport and trade, which we denote by $U$ (Fig. A.1).

Let $C_{j-\text { - }}$ be the $\mathrm{CO}_{2}$ emissions of industry $j$ through combustion of fuel and use of electricity. $C_{-k e}$ is the $\mathrm{CO}_{2}$ emissions of the final supply of products $k$ as used for final demand by expenditure $e$. The matrix of $C_{-k}$ - for $k=4$ to 6 is

$\left[\begin{array}{lll}b_{44-} & b_{54-} & b_{64-} \\ b_{45-} & b_{55-} & b_{65-} \\ b_{46-} & b_{56-} & b_{66-}\end{array}\right]\left[\begin{array}{l}C_{4--} \\ C_{5--} \\ C_{6--}\end{array}\right]=\left[\begin{array}{l}C_{-4-} \\ C_{-5-} \\ C_{-6-}\end{array}\right]$

\section{C.2 Including apportioned inputs or impacts to GFCF within FCF of each industry and dwellings}

One component of final demand is GFCF. Since we can regard this as another type of input to enable production, we show a method for reassigning the $\mathrm{CO}_{2}$ emission footprint of GFCF according to each industry's demand for GFCF, this being its FCF. First we subtract $\mathrm{CO}_{2}$ emissions of each product going to GFCF according to their pGFCF coefficients (Fig. A.1). For $C_{--e}$ we set $e=1$ for GFCF with $\mathrm{e}=2$ for AFC of households and $\mathrm{e}=3$ for 
SH. Roberts, CJ. Axon, NH. Goddard, BD. Foran, \& BS. Warr (2019). Modelling socio-economic and energy data to generate business-as-usual scenarios for carbon emissions. J. Cleaner Production, 207, pp.980-997. https://doi.org/10.1016/j.jclepro.2018.10.029

exports. Let $h_{-k e}$ be the proportion of final demand for each product, $g_{e}$, going to type of final expenditure, $e$. We can obtain the vector of $C_{-k e}$

$\left[\begin{array}{l}h_{-41} \\ h_{-51} \\ h_{-61}\end{array}\right]\left[\begin{array}{l}C_{-4-} \\ C_{-5-} \\ C_{-6-}\end{array}\right]=\left[\begin{array}{l}C_{-41} \\ C_{-51} \\ C_{-61}\end{array}\right]$

The total $\mathrm{CO}_{2}$ emissions footprint of GFCF is

$C_{--1}=\sum_{\mathrm{k}=4}^{6} C_{-k 1}$

We can also derive the $\mathrm{CO}_{2}$ emissions contribution by each industry to GFCF

$\left[\begin{array}{lll}b_{44-} & b_{45-} & b_{46-} \\ b_{54-} & b_{55-} & b_{56-} \\ b_{64-} & b_{65-} & b_{66-}\end{array}\right]\left[\begin{array}{l}h_{-41} \cdot C_{4--} \\ h_{-51} \cdot C_{5--} \\ h_{-61} \cdot C_{6--}\end{array}\right]=\left[\begin{array}{l}C_{4-1} \\ C_{5-1} \\ C_{5-1}\end{array}\right]$.

We distribute the GFCF emissions across just the larger FCF users which are the three larger industries $(j=4$ to 6) together with $d w l g, j=7$. Let $D_{j--}$ be the $\mathrm{CO}_{2}$ emissions of industry $j$, less their emissions contribution to all of GFCF ( $e=1)$, plus the emissions of their own need for FCF,

$$
D_{j--}=C_{j--}-C_{j-1}+\frac{\left(C_{--1} \cdot F C F_{j}\right)}{\sum_{j=4}^{7} F C F_{j}} .
$$

Let $D_{\text {-k- }}$ be the $\mathrm{CO}_{2}$ emissions of the final supply of products $k$ including the emissions apportioned to FCF as part of production. We obtain the matrix of $D_{-k-}$ for $k=4$ to 6 in a similar form to Equation (C.3),

$\left[\begin{array}{lll}b_{44-} & b_{54-} & b_{64-} \\ b_{45-} & b_{55-} & b_{65-} \\ b_{46-} & b_{56-} & b_{66-}\end{array}\right]\left[\begin{array}{l}D_{4--} \\ D_{5--} \\ D_{6--}\end{array}\right]=\left[\begin{array}{c}D_{-4-} \\ D_{-5-} \\ D_{-6-}\end{array}\right]$.

For $d w l g$, we take as their direct emissions, $\mathrm{C}_{7-\text {-., }}$ as resulting from their own combustion of fuels and use of electricity. We denote total $\mathrm{CO}_{2}$ emissions associated with $d w l g$, where we now include FCF,

$$
D_{7--}=D_{-7-}=C_{7--}+\frac{\left(C_{--1} \cdot F C F_{7}\right)}{\sum_{j=4}^{7} F C F_{j}} .
$$

